Article

\title{
Experimental Research on Mechanical and Permeability Properties of Nylon Fiber Reinforced Recycled Aggregate Concrete with Mineral Admixture
}

\author{
Jawad Ahmad ${ }^{1}\left(\mathbb{D}\right.$, Osama Zaid ${ }^{1, * \mathbb{D}}$, Carlos López-Colina Pérez ${ }^{2} \mathbb{D}$, Rebeca Martínez-García ${ }^{3}$ (D) \\ and Fernando López-Gayarre ${ }^{2, *(D)}$
}

check for

updates

Citation: Ahmad, J.; Zaid, O.; Pérez,

C.L.-C.; Martínez-García, R.;

López-Gayarre, F. Experimental

Research on Mechanical and

Permeability Properties of Nylon

Fiber Reinforced Recycled Aggregate

Concrete with Mineral Admixture.

Appl. Sci. 2022, 12, 554. https://

doi.org/10.3390/app12020554

Academic Editors: Lorena Zichella

and Dario De Domenico

Received: 9 November 2021

Accepted: 22 December 2021

Published: 6 January 2022

Publisher's Note: MDPI stays neutral with regard to jurisdictional claims in published maps and institutional affiliations.

Copyright: (C) 2022 by the authors. Licensee MDPI, Basel, Switzerland. This article is an open access article distributed under the terms and conditions of the Creative Commons Attribution (CC BY) license (https:// creativecommons.org/licenses/by/ $4.0 /)$.
1 Department of Civil Engineering, Military College of Engineering, National University of Sciences and Technology, Islamabad 44000, Pakistan; jawadcivil13@scetwah.edu.pk

2 Department of Construction, Campus de Gijón, University of Oviedo, 33203 Gijón, Spain; lopezpcarlos@uniovi.es

3 Department of Mining Technology, Topography, and Structures, Campus de Vegazana s/n, University of León, 24071 León, Spain; rmartg@unileon.es

* Correspondence: osamazaidmarwat@gmail.com (O.Z.); gayarre@uniovi.es (F.L.-G.)

\begin{abstract}
Plain concrete's major two drawbacks are its low tensile strength and high carbon footprint. Joint adding of fibers and recycled/waste materials in concrete might assist to resolve these problems. In the present study, a novel technique is planned to improve the recycled aggregate concrete (RAC) mechanical behavior and durability performance by joint incorporation of silica fume (SF) and nylon fibers (NF). In this research paper, different properties of concrete samples are examined for example flexural strength, compressive strength, split tensile strength, penetration of chloride ions, acid resistance, and water absorption. It was noted that adding nylon fibers as individual components enhances the recycled aggregate concrete mechanical characteristics and resistance to acid exposure. The inclusion of nylon fibers improved the behavior of the recycled aggregate concrete; however, it also increased the chloride penetration and water absorption by only $18 \%$ and $8 \%$ respectively. Up to $26 \%$ of mechanical strength of concrete was improved when silica fume was added in comparison to reference concrete, silica fume also assisted in controlling the loss of durability because of adding recycled aggregate concrete and nylon fibers. Silica fume improved the bond between binder matrix and nylon fibers. The study revealed that the combination of 50\% RCA, $0.5 \%$ nylon fibers and $20 \%$ silica fume are optimum for the joint incorporation into concrete that can assist in developing sustainable, durable, and ductile recycled aggregate fiber reinforced concrete.
\end{abstract}

Keywords: sustainable concrete; silica fume; nylon fibers; recycled aggregate

\section{Introduction}

Presently, numerous countries throughout the world are confronting a large deficiency of landfills to discard huge amounts of various construction and demolition wastes due to huge development of infrastructure. In nations, where development is emerging quickly also increased infrastructure construction and demolition wastes, which leads to increased generation of CDW [1]. In developing nations, a significant part of CDW is causing landfills because of the lack of appropriate reusing methods, which makes social complexities and environmental issues. In 2018 it was calculated that 40 developing nations around the planet, created more than 3000 million tons of CDW [2,3]. Using appropriate crushing techniques, CDW could be changed into recycled aggregate. Land pollution can be significantly reduced by substituting normal weight aggregates with recycled concrete aggregates. Author is study revealed successful utilization of RAC in various pavement and building structures [4]. Currently, cement production is increasing quickly to meet the request for infrastructure development. Cement production was approximately 4111.1 million tons 
annually in 2018 and this demand is rapidly rising $[5,6]$. Presently, more than $5 \%$ of worldwide $\mathrm{CO}_{2}$ emission is because of the cement industry $[7,8]$. Supplementary cementitious materials can be used as partial replacement materials to meet the cement demands. SCMs such as silica fume could be used to decrease the carbon footprint of cement effectively [9].

Comparatively recycled aggregate concrete has lesser mechanical strength as compared to normal aggregate concrete NWA [10]. To enhance the RAC behavior, authors $[9,11]$ have suggested using chemical admixtures and mineral additives (such as fly ash, chemical plasticizers, silica fume, GGBFS, etc.), fibers (such as nylon, steel, glass, etc.) Silica fume offers great potential to be used as a mineral additive attributable to its overall accessibility at a less expensive cost. Different researchers have assessed the RAC performance with silica fume. These investigations disclose that silica fume credits more to the RAC properties when compared to normal aggregate concrete NAC. Authors in a study [9] observed that utilization of both silica fume and RCA is not favorable to concrete compressive strength but at reasonable levels for example at the same level of workability, 3\% reduction was noted in compressive strength of 90 days when $100 \%$ normal aggregate concrete NAC was substituted with RAC, while $4 \%$ reduction was observed when cement was $30 \%$ substituted with silica fume. In pozzolanic reaction, silica fume may react with $\mathrm{C}-\mathrm{H}$ which is a cement hydration primary product existing in RAC old paste of binder and new paste of binder, this is the reason silica fume contributes more to the RAC hardened properties. Researchers $[12,13]$ revealed that silica fume also adds more to the durability of RAC as compared to NWA concerning chloride penetration, sorptivity, water absorption.

Most of researches on fiber reinforced concrete were performed on steel fibers [12,14-20]. Very few researches were performed on nylon fibers [21-23] according to the author's knowledge. Nylon fibers are utilized in the production of different products such as carpets, rope, clothes, tires, and other durable materials. Nylon is a synthetic material. Nylon is thermoplastic silky material that can be melted and processed" into different shapes such as "films, fibers, or shapes" [24]. The reason for adopting nylon fiber is that it has good hardness, resilience, and durability characteristics; and it is readily accessible in various colors, can be dyed, resistant to soil and dirt, good abrasion properties, and also accessible in different cross-sections [25].The nylon fibers affect the environment and the discarding of these fibers in a usable way will reduce its detrimental effect on the environment [26]. Nylon is heat stable, hydrophilic, relatively inactive, and resistant to a wide variety of materials. Nylon is most effective in adding impact resistance and flexural toughness and sustaining the increased load-carrying capacity of concrete after the first crack [27]. The utilization of nylon fiber as an ingredient in cement concrete is promising as it provides an alternate method of disposal of fibers because these materials will enhance the strength and durability of concrete [23]. The inclusion of nylon fiber has also been reported to enhance durability of concrete. Fibers protect the concrete cover from spalling because of the good bonding behavior [26,28].

Using different types of fiber reinforcement to improve RAC mechanical behavior is not a new method. Various types of fibers, for example, basalt fibers [29], polypropylene [30], glass [31], and steel [26] etc. have been used in RAC. These researchers revealed that upon RAC fiber reinforcement enhanced its flexural strength, split tensile strength, and compressive strength. Because of the fiber reinforcement crack bridging effect, RAC flexural and split tensile strength was more improved in comparison to its compressive strength [26]. Authors in a study [32] have revealed detrimental effects of fibers on RAC and normal aggregate concrete durability-related aspects (sorptivity, chloride penetration, water absorption, etc.). Researchers in a study [32] have noted the positive effect of steel fibers on (RAC) resistance to acid exposure because of the enhanced binder matrix integrity. They also reported [32] that mineral admixtures such as wheat straw ash or RHA etc., might enhance the binder matrix bonding with fibers, therefore durability and mechanical characteristics of RAC could be improved with joint use of fibers and SCMs. Fiber reinforcement reduces the workability of concrete which leads to more demands of superplasticizer to keep up the concrete workability in the required range [33]. Authors in a study [34] revealed that the use of silica fume in glass fiber reinforced concrete mix, could enhance 
the fresh concrete workability; hence admixture cost could be reduced. They also revealed that glass fiber could also reduce the early strength loss in silica fume blends by enhancing the integrity of the concrete.

The utilization of SCMs in normal aggregate concrete with various fibers has been examined widely [34-36]. There are very few observations [28,32,35] that have tested (RAC) performance with joint utilization of mineral admixtures and fibers. Authors in research [37] noted that SCMs such as fly ash can be successfully used to improve the bond of binder matrix with steel fibers [38-41], which leads to improvement of RAC flexural and compressive strength. They also revealed that the combined adding of steel fibers and silica fume can greatly improve the RAC performance after elevated temperature exposures. Though, very few observations $[32,37]$ have examined the impact of joint adding of mineral admixtures and fibers to improve the RAC mechanical and durability performance.

\section{Research Significance}

A brief literature review showed that RAC decreased the mechanical performance and durability aspects of concrete due its porous nature. Therefore, it is necessary to add waste mineral admixture (such as silica fume) to RAC to offsets its porous nature by filling voids and improve inter transition zone due to pozzolanic reaction which enhances binding property of concrete. Although, mechanical performance and durability characteristics of RAC were considerably improved by addition of supplementary cementitious materials, but concrete still had less tensile capacity which can result in brittle failure without giving any warning, so concrete need reinforcement to improve its tensile strength. Therefore, concrete needed tensile reinforcements to enhance tensile capacity of concrete and offsets undesirable brittle failure. Fibers are one of the most prevalent method to increased tensile capacity of concrete. In addition, studies show that $[7,8]$ fiber enhances tensile capacity more effectively than compressive strength. Supplementary cementitious materials could be added to fibers reinforced concrete, to obtain high strength ductile durable concrete.

The goal of the present research was to thoroughly research the combined influence of nylon fibers and silica fume on RAC and NAC mechanical characteristics and durability related permeability properties. Recycled aggregate was acquired by using recycled concrete aggregate. Silica fume was added by a volume of $20 \%$ as a substitute for cement in both RAC and NAC. Nylon fibers were utilized as $0.5 \%$ to strengthen concrete blends. Different characteristics of concrete-like flexural strength, compressive strength, split tensile strength, water absorption, chloride penetration, and concrete exposure to acid were assessed.

\section{Materials}

\subsection{Silica Fume}

Silica fume was obtained from Hattar industrial state, Pakistan. Its physical characteristics are displayed in Table 1.

Table 1. Physical Properties of Silica fume.

\begin{tabular}{cc}
\hline Physical Properties & Results \\
\hline Color & Light Grey \\
Specific Gravity & 2.61 \\
Clay & $0.6 \%$ \\
Bulk density & $1480 \mathrm{~kg} / \mathrm{m}^{3}$ \\
Fineness Modulus & 2.51 \\
\hline
\end{tabular}

\subsection{Cement}

Ordinary Portland cement Type I [42] was used for the current research its physical properties and chemical composition are presented in Table 2. 
Table 2. Physical Properties of Portland Cement.

\begin{tabular}{cc}
\hline Physical Properties & Results \\
\hline Size & $\leq 75 \mu \mathrm{m}$ \\
Fineness & $92 \%$ \\
Normal Consistency & $31 \%$ \\
Initial setting time & $33 \mathrm{~min}$ \\
Final setting time & $409 \mathrm{~min}$ \\
Specific surface & $322 \mathrm{~m}^{2} / \mathrm{kg}$ \\
Soundness & $1.70 \%$ \\
Compressive strength (at 28 days) & $42 \mathrm{MPa}$ \\
\hline
\end{tabular}

\subsection{Aggregates}

Natural river sand was utilized as fine aggregate for the present study. Crushed stone was used as coarse aggregate, which was acquired from Margalla, Punjab. RCA was made by manually crushing concrete samples which had a compressive strength of 35 to $40 \mathrm{MPa}$. Fine and coarse (natural + recycled) aggregates physical properties are presented in Table 3.

Table 3. Physical Properties of Fine and Coarse Aggregates.

\begin{tabular}{cccc}
\hline Physical Properties & Fine Aggregate & Coarse Aggregate & $\begin{array}{c}\text { Recycled Coarse } \\
\text { Aggregate }\end{array}$ \\
\hline Particle size $(\mathrm{mm})$ & 4.75 to 0.75 & 25 to 4.75 & 25 to 4.75 \\
Bulk density $\left(\mathrm{kg} / \mathrm{m}^{3}\right)$ & 1570 & 1581 & 1495 \\
Absorption capacity $(\%)$ & 4.11 & 2.85 & 4.7 \\
Moisture content $(\%)$ & 1.75 & 1.3 & 2.8 \\
Fineness modulus & 2.58 & 4.31 & 5.2 \\
\hline
\end{tabular}

\subsection{Nylon Fibers}

The nylon fibers used in this study were acquired from a locally available commercial market in Rawalpindi, Pakistan. Its properties are given in Table 4.

Table 4. Physical Properties of Nylon Fibers.

\begin{tabular}{cc}
\hline Physical Properties & Nylon Fibers \\
\hline Color & White \\
Length $(\mathrm{mm})$ & 20 \\
Diameter $(\mathrm{um})$ & 24 \\
Aspect ratio & 833 \\
Density $\left(\mathrm{g} / \mathrm{cm}^{3}\right)$ & 1.21 \\
Tensile Strength $(\mathrm{MPa})$ & 921 \\
Elastic Modulus $(\mathrm{GPa})$ & 5.4 \\
\hline
\end{tabular}

\section{Mixing Procedure}

ACI 211.1 [43] was followed for the concrete mix design, twelve concrete blends were prepared totally. RCA was substituted with NCA as $0 \%, 50 \%$, and $100 \%$ by volume. Silica fume was substituted $20 \%$ with cement. To make nylon fiber reinforced concrete, a nylon fiber of $0.5 \%$ fraction volume was utilized. The nomenclature and composition of every concrete mixture are displayed in Table 5 . Extra water $\left(85 \mathrm{~kg} / \mathrm{m}^{3}\right)$ was added to blends utilizing RCA, to recompense RCA water absorption during the process of mixing. Recycled concrete aggregate was used in a completely dried condition in the mixture, so extra water was needed for RAC. Regardless of adding extra water, constant water to cement ratio was chosen for all concrete mixes. Utilizing nylon fibers reduced the fresh concrete workability, therefore, chemrite-530 [44] was added to keep the desired range of slump $85 \mathrm{~mm}-105 \mathrm{~mm}$ throughout the concrete mixes. Aggregate content is reduced to oblige $0.5 \%$ fraction content of nylon fibers in samples. Concrete was mixed in the 
mixer which had the capacity of $0.20 \mathrm{~m}^{3}$ at rate of 15 revs/minute. Firstly, aggregates were blended for $5 \mathrm{~min}$ with half of needed water. Next $5 \mathrm{~min}$, nylon fibers, cement, and lasting half of the water were introduced to the concrete mixer, and the concrete was mixed for more than $7 \mathrm{~min}$. The complete period of mixing duration was $12 \mathrm{~min}$. This method permits recycled concrete aggregate to absorb sufficient water (over $80 \%$ of recycled concrete aggregate's 24-h absorption capacity) as recommended by past researches [9].

Table 5. Concrete Mixture Nomenclature and Ingredients Quantity in Cubic Meter.

\begin{tabular}{|c|c|c|c|c|c|c|c|c|}
\hline \multirow[t]{2}{*}{ Mix ID } & \multicolumn{2}{|c|}{ Binder $\left(\mathrm{kg} / \mathrm{m}^{3}\right)$} & \multirow[t]{2}{*}{$\begin{array}{c}\text { Fine } \\
\text { Aggregate } \\
\left(\mathrm{kg} / \mathrm{m}^{3}\right)\end{array}$} & \multicolumn{2}{|c|}{$\begin{array}{c}\text { Coarse Aggregate } \\
\left(\mathrm{kg} / \mathrm{m}^{3}\right)\end{array}$} & \multirow[t]{2}{*}{$\begin{array}{c}\text { Water } \\
\left(\mathrm{kg} / \mathrm{m}^{3}\right)\end{array}$} & \multirow[t]{2}{*}{ NF (kg) } & \multirow[t]{2}{*}{ SP (kg) } \\
\hline & Cement & Silica Fume & & NCA & RCA & & & \\
\hline RCA0-SF0-PC & 380 & 0 & 780 & 1080 & 0 & 190 & 0 & 0 \\
\hline RCA50-SF0-PC & 380 & 0 & 780 & 540 & 476 & 190 & 0 & 0 \\
\hline RCA100-SF0-PC & 380 & 0 & 780 & 0 & 951 & 190 & 0 & 0 \\
\hline RCA0-SF20-PC & 304 & 76 & 780 & 1080 & 0 & 190 & 0 & 0 \\
\hline RCA50-SF20-PC & 304 & 76 & 780 & 540 & 476 & 190 & 0 & 0 \\
\hline RCA100-SF20-PC & 304 & 76 & 780 & 0 & 951 & 190 & 0 & 0 \\
\hline RCA0-SF0-NFRC & 380 & 0 & 780 & 1074 & 0 & 190 & 13 & 2 \\
\hline RCA50-SF0-NFRC & 380 & 0 & 780 & 537 & 471 & 190 & 13 & 2 \\
\hline RCA100-SF0-NFRC & 380 & 0 & 780 & 0 & 945 & 190 & 13 & 2 \\
\hline RCA0-SF20-NFRC & 304 & 76 & 780 & 1074 & 0 & 190 & 13 & 2 \\
\hline RCA50-SF20-NFRC & 304 & 76 & 780 & 537 & 471 & 190 & 13 & 2 \\
\hline RCA100-SF20-NFRC & 304 & 76 & 780 & 0 & 945 & 190 & 13 & 2 \\
\hline
\end{tabular}

\section{Sample Preparation, Size, and Test of Sample}

For mechanical performance, three main aspects were defined for example flexural strength, compressive strength, and split tensile strength. Compressive strength for all concrete samples was determined at 7,28, and 90 days of curing. Concrete cylinders that had a height of $300 \mathrm{~mm}$ and a diameter of $150 \mathrm{~mm}$ were prepared and then tested as per ASTM C 39 [45]. To evaluate split tensile strength, cylinders that had a height of $300 \mathrm{~mm}$ and diameter of $150 \mathrm{~mm}$ were prepared and then tested at 28 and 90 days of curing as per ASTM C 496 [46]. The flexural strength of concrete samples was measured using samples that had the size of $100 \mathrm{~mm} \times 100 \mathrm{~mm} \times 500 \mathrm{~mm}$ at 28 and 90 days of curing as per ASTM C 78 [47].To bring uniformity to the research, three samples for each test were prepared and tested and their average value was taken as the final value for that test.

To determine the durability performance, acid resistance of concrete, water absorption, and chloride penetration tests were performed. To evaluate the impact of sulfuric acid $\left(\mathrm{H}_{2} \mathrm{SO}_{4}\right)$ attack on each concrete sample. Cubical samples with a size of $100 \mathrm{~mm}$ were utilized. These samples were placed in a tap water tank for 28 days. Samples were ovendried at $45{ }^{\circ} \mathrm{C}$ for one day after curing, then the samples were placed in a $5 \%\left(\mathrm{H}_{2} \mathrm{SO}_{4}\right)$ chemical for the acid test. Variation in the mass of samples is calculated at 28, 56, 90, and 120 days of specimens placed in acid. Variation in sample mass was measured by calculating sample mass before and after its placement in $5 \%\left(\mathrm{H}_{2} \mathrm{SO}_{4}\right)$. Water absorption of concrete samples was measured following ASTM C1585 [48]. Concrete samples which had a diameter of $100 \mathrm{~mm}$ and thickness of $50 \mathrm{~mm}$ were prepared and tested for water absorption test at 28 and 90 days of curing. For the chloride penetration test, samples in cylinder shape which had $100 \mathrm{~mm}$ height and $100 \mathrm{~mm}$ diameter were prepared. These samples were placed in a tap water tank for 28 days for curing. Samples were oven-dried at $45{ }^{\circ} \mathrm{C}$ for one day after curing, then the samples were placed in $5 \%$ sodium chloride chemical for 56 days. After placement of samples, samples were cut open, and spray was used on the failure surface with silver nitrate $\left(\mathrm{AgNO}_{3}\right)$ solution with a normality of $0.1 \mathrm{~N}$ in water. Silver nitrate reacted with penetrated chloride and left silver color which shows the formation of silver chloride $(\mathrm{AgCl})$ on the surface of failure which shows the sign of 
the depth of chloride penetration into samples. These penetrations were calculated at five various spots along the failed sample periphery. The same technique was also used by the author in a study [49].

\section{Results}

\subsection{Compressive Strength}

As concrete is the most versatile construction material, it is for the most part used to take the load in compression. Concrete mix standard deviation and coefficient of variation and compressive strength and was evaluated at 7, 28, and 90 days of curing as appeared in Figure 1 and Table 6 respectively. RCA's highest compressive strength was obtained with the mix having nylon fibers and $20 \%$ of silica fume, followed by the mixture which had $0 \%$ silica fume and nylon fibers. Increasing the dosage of RCA reduces the compressive strength of concrete. Compressive strength of concrete at 28 days decreases by $7 \%$ at $50 \%$ RCA and $15 \%$ at $100 \%$ RCA replacement. Recycled aggregate concrete reduced compressive strength as a comparison to normal aggregate concrete could be attributed to the existence of a greater number of interfacial transition zones ITZs in recycled aggregate concrete as compared to normal aggregate concrete. In recycled aggregate concrete ITZs has four types: (1) between the old and new mortar; (2) ITZ between old mortar and natural stone recycled concrete aggregate; (3) between new mortar and natural concrete aggregate; and (4) between natural stone recycled concrete aggregate and new mortar [50]. In the natural aggregate concrete, there is only one ITZ that is present between fresh mortar and natural aggregate. The existence of multiple ITZs can cause the failure of early bonding in the case of recycled aggregate concrete under compression; hence, recycled aggregate concrete RAC compressive strength is significantly lower as compared to normal aggregate concrete NAC. Furthermore, the water requirement to fulfill the water absorption of aggregates in the case of RAC mixes is very high as compared to NAC, which could also be the significant factor that leads to reduced compressive strength. Though adding more water resolves concrete workability issues, it could cause in concrete with lower compressive strength [11]. Adding 20\% silica fume does not have a major effect on the compressive strength of concrete at 7 days of curing. Concrete samples cured at 28 and 90 days, which had silica fume performed considerably better as compared to sample with no silica fume. For example, RCA0-SF20 displays 3\% and 7\% more compressive strength as compared to RCA0-SF0 28 and 90 days of curing. This could be attributed to the pozzolanic reaction amid free $\mathrm{C}-\mathrm{H}$ and silica fume particles. Silica fume does not only decrease the $\mathrm{C}-\mathrm{H}$ amount of cement matrix by changing it to C-S-H gel, but it also enhances the dispersal of particle size in the cement matrix by filling the voids amid fine aggregates and particles of cement. This causes enhancement of compressive performance of concrete samples having $20 \%$ silica fume [51]. RCA mixes that had silica fume gained more compressive strength as compared to NCA concrete blends.

RCA50-SF20, and RCA100-SF20 exhibit 6\% more gain in compressive strength as compared to their cement-based mixes at 90 days of curing. RCA50-SF20 shows more compressive strength at 28 and 90 days of curing as compared to the reference sample (RCA0-SF0). While at 90 days of curing RCA100-SF20 exhibits comparable compressive strength. Anyway, silica fume ascribed to the concrete either utilizing RCA or NCA as aggregate, displays more compatibility with recycled concrete aggregate as compared to natural concrete aggregate. Past researches $[9,52]$ have ascribed this to a raise in $\mathrm{C}-\mathrm{H}$ amount of concrete with increasing doses of recycled concrete aggregate. Since recycled concrete aggregate has adhered mortar containing un-hydrated $\mathrm{C}-\mathrm{H}$, particles of silica fume may react with ITZs between new mortar and old mortar. That causes the ITZs strengthening which leads to improved concrete behavior under external loading. 


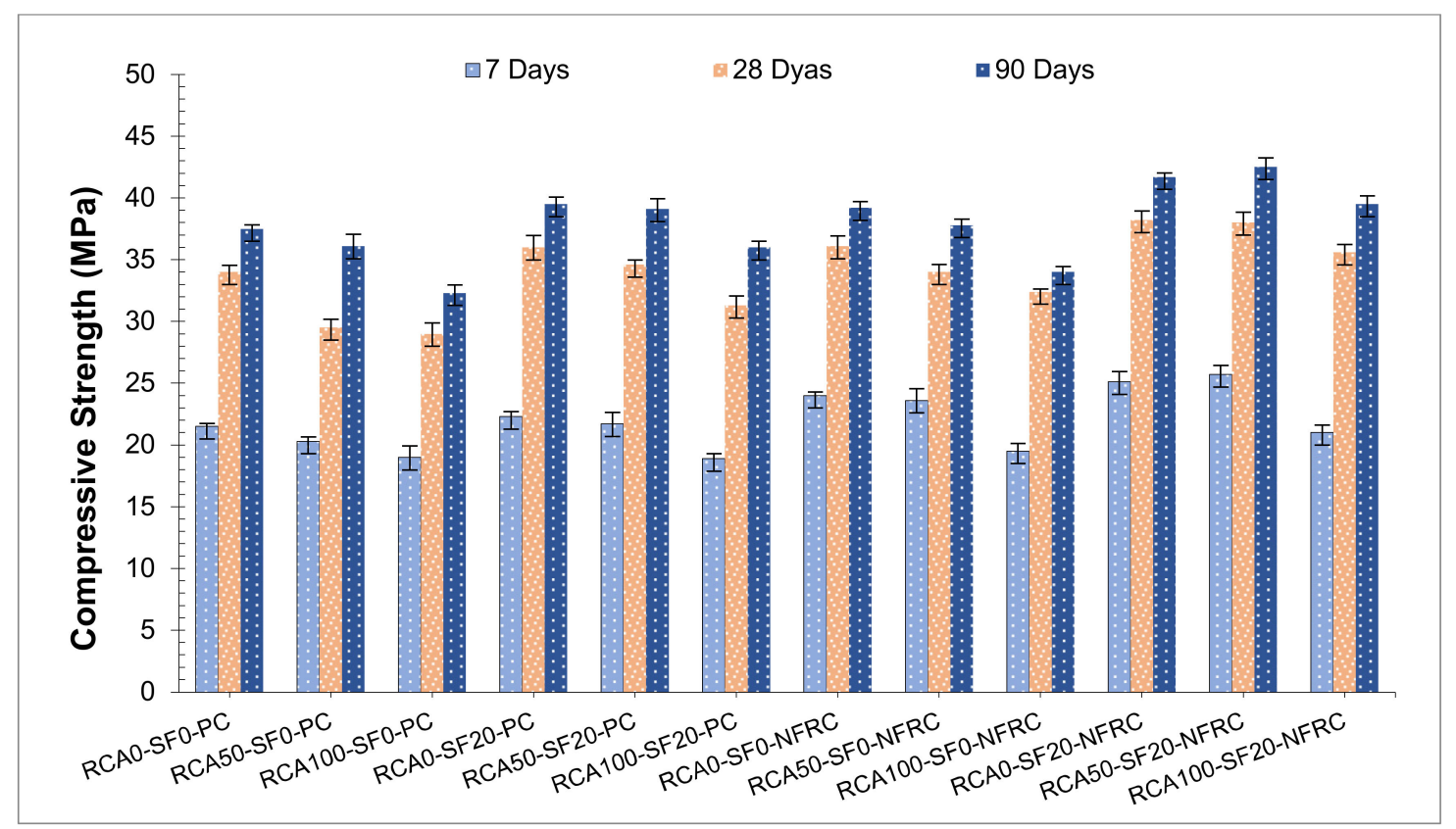

(a)

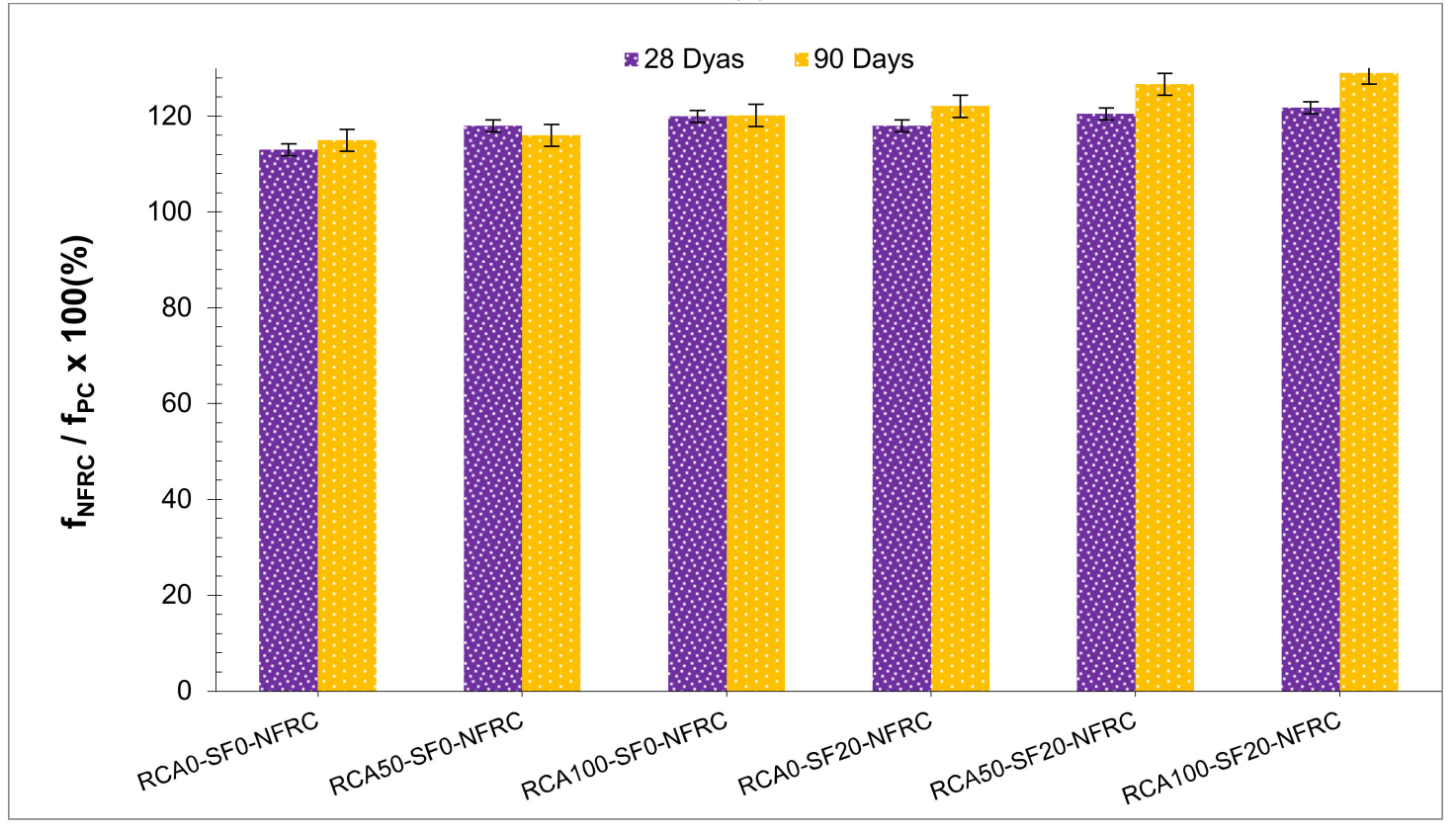

(b)

Figure 1. (a) Compressive Strength (b) Compressive Strength of Each NFRC Mix w.r.t Plain Concrete $(\mathrm{PC})$. 
Table 6. Standard Deviation and Coefficient of Variation for Compressive Strength (MPa).

\begin{tabular}{ccccccc}
\hline \multirow{2}{*}{ Mix ID } & \multicolumn{2}{c}{ 7 Days } & \multicolumn{2}{c}{ 28 Days } & \multicolumn{2}{c}{ 90 Days } \\
\cline { 2 - 6 } & $\begin{array}{c}\text { Standard } \\
\text { Deviation }\end{array}$ & $\begin{array}{c}\text { Coefficient of } \\
\text { Variance }\end{array}$ & $\begin{array}{c}\text { Standard } \\
\text { Deviation }\end{array}$ & $\begin{array}{c}\text { Coefficient of } \\
\text { Variance }\end{array}$ & $\begin{array}{c}\text { Standard } \\
\text { Deviation }\end{array}$ & $\begin{array}{c}\text { Coefficient of } \\
\text { Variance }\end{array}$ \\
\hline RCA0-SF0-PC & 0.25 & 2.26 & 0.550 & 4.734 & 0.321 & 2.649 \\
RCA50-SF0-PC & 0.35 & 2.86 & 0.680 & 5.641 & 0.971 & 7.853 \\
RCA100-SF0-PC & 0.92 & 5.93 & 0.888 & 7.226 & 0.655 & 4.342 \\
RCA0-SF20-PC & 0.4 & 2.35 & 0.986 & 5.826 & 0.568 & 3.261 \\
RCA50-SF20-PC & 0.95 & 9.63 & 0.404 & 2.618 & 0.862 & 8.425 \\
RCA100-SF20-PC & 0.4 & 3.52 & 0.763 & 7.983 & 0.5 & 4 \\
RCA0-SF0-NFRC & 0.3 & 2.38 & 0.850 & 7.310 & 0.529 & 3.948 \\
RCA50-SF0-NFRC & 0.96 & 6.02 & 0.611 & 4.037 & 0.5 & 3.448 \\
RCA100-SF0-NFRC & 0.65 & 3.74 & 0.251 & 1.4085 & 0.458 & 2.618 \\
RCA0-SF20-NFRC & 0.86 & 8.42 & 0.754 & 6.801 & 0.346 & 3.207 \\
RCA50-SF20-NFRC & 0.75 & 6.74 & 0.854 & 8.993 & 0.763 & 5.951 \\
RCA100-SF20-NFRC & 0.63 & 6.93 & 0.650 & 5.437 & 0.680 & 4.944 \\
\hline
\end{tabular}

The compressive strength of nylon fiber reinforced concrete is more as compared to a reference sample. Strengthening to cement matrix is provided by nylon fibers and aids in controlling crack propagation. Because of the RCA utilization, nylon fibers recuperate some loss of $4 \%$ concerning the reference sample. Net increase in compressive strength because of the nylon fibers addition is more in concrete mixes having silica fume as compared to mixes with no silica fume. For example, concrete samples with silica fume exhibit a net increase of (3-10\%) over the reference sample in compressive strength while, concrete samples with no silica fume exhibit (3-5\%) net increase only, it can be seen in Figure 1. This might be attributable to enhancement in the bond of cement paste matrix and fibers because of adding silica fume. Silica fume particles are very finer as compared to cement, it could increase binder surface area over nylon fibers. Hence, SF can enhance the bond of binder matrix with nylon fibers, and mixed with silica fume exhibits more gain in compressive strength as compared to mixes with no silica fume. A study of bonds performed by [53] revealed that utilizing SCMs such as fly ash can improve the ITZ of binder matrix with the fibers, which need more increased effort to pull out strands from the cement. This assisted in improving cement-based composite's mechanical strength. Similar to fly ash, the potential of $\mathrm{C}-\mathrm{H}$ consumption and the filler effect of silica fume could also reinforce the ITZ between binder matrix and nylon fibers.

A relative analysis of compressive strength tests is shown in Figure 2. A relative analysis is performed on concrete samples to show that how much its performance is improved concerning the control sample. It was observed that using nylon fiber and silica fume, RCA level can be exploited to obtain comparable or better performance as compared to the reference sample. For example, RCA50-SF20 and RCA50-SF20-NFRC exhibit similar and improved performance as compared to the reference sample at 28 days of curing. Likewise, at 90 days of curing RCA100-SF20 and RCA100-SF20-NFRC display improved performance as compared to the reference sample at 28 days of curing. It can be concluded that the joint utilization of silica fume, nylon fiber can assist to enhance the RAC performance. 


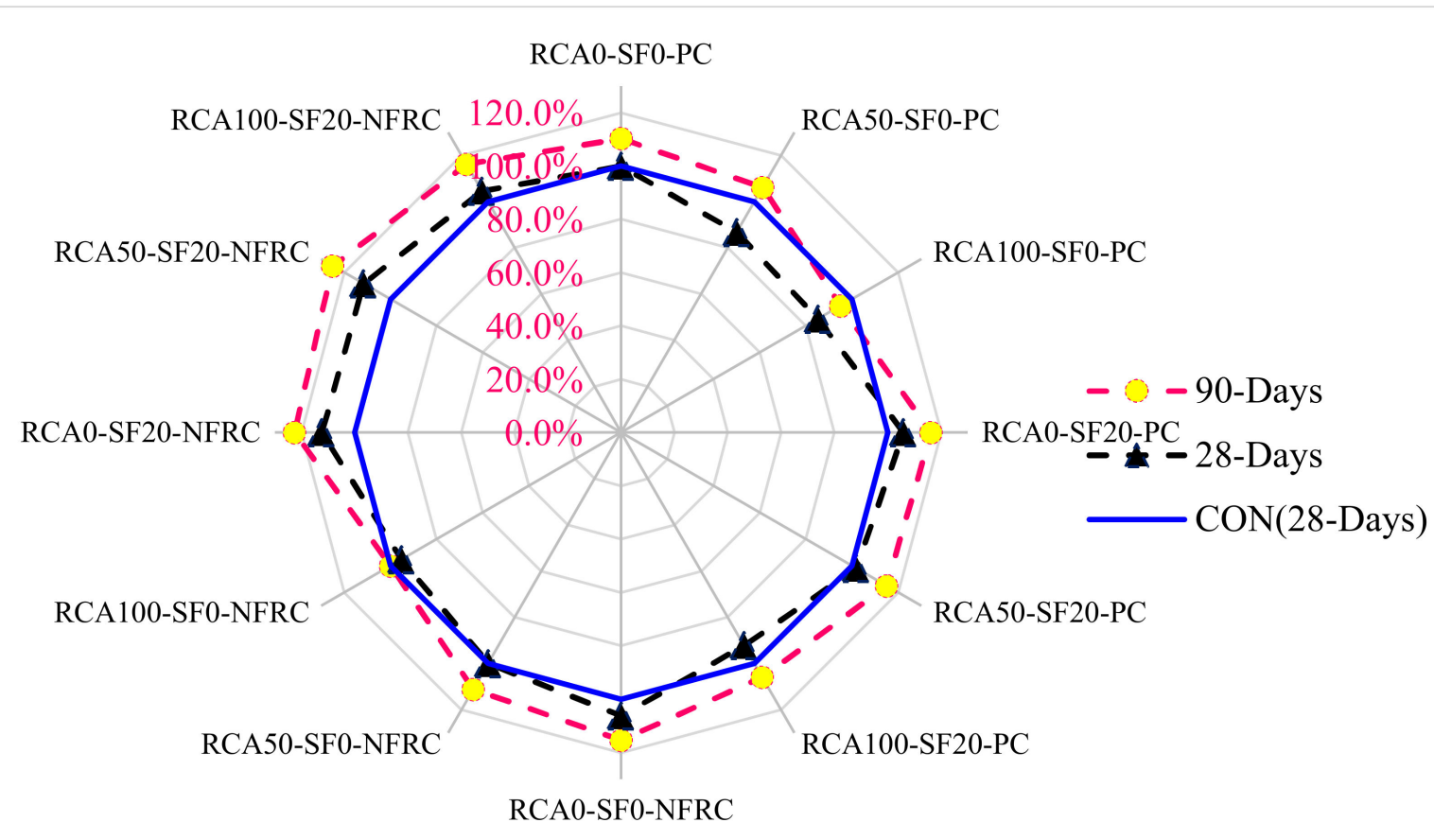

Figure 2. Relative Analysis of Compressive Strength.

\subsection{Split Tensile Strength}

Test results and standard deviation and coefficient of variation of split tensile strength for all concrete samples are provided in Figure 3 and Table 7. Results overview demonstrates that recycled concrete aggregate is marginally detrimental to concrete tensile strength, while nylon fiber reinforced concrete has particularly more split tensile strength as compared to reference plain concrete sample.

Table 7. Standard Deviation and Coefficient of Variation of Split Tensile Strength (MPa).

\begin{tabular}{ccccc}
\hline \multirow{2}{*}{ Mix ID } & \multicolumn{2}{c}{ 28 Days } & \multicolumn{2}{c}{ 90 Days } \\
\cline { 2 - 5 } & Standard Deviation & Coefficient of Variance & Standard Deviation & Coefficient of Variance \\
\hline RCA0-SF0-PC & 0.550 & 3.568 & 0.208 & 1.366 \\
RCA50-SF0-PC & 0.737 & 4.860 & 0.436 & 2.750 \\
RCA100-SF0-PC & 0.7 & 5.691 & 0.450 & 2.847 \\
RCA0-SF20-PC & 0.929 & 5.943 & 0.351 & 2.351 \\
RCA50-SF20-PC & 0.438 & 2.803 & 0.577 & 4.570 \\
RCA100-SF20-PC & 0.346 & 2.220 & 0.458 & 2.975 \\
RCA0-SF0-NFRC & 0.945 & 6.329 & 0.754 & 4.689 \\
RCA50-SF0-NFRC & 0.404 & 3.224 & 0.450 & 2.841 \\
RCA100-SF0-NFRC & 0.655 & 4.285 & 0.680 & 4.497 \\
RCA0-SF20-NFRC & 0.490 & 3.129 & 0.503 & 3.921 \\
RCA50-SF20-NFRC & 0.305 & 1.941 & 0.358 & 2.314 \\
RCA100-SF20-NFRC & 0.828 & 5.383 & 0.929 & 5.943 \\
\hline
\end{tabular}




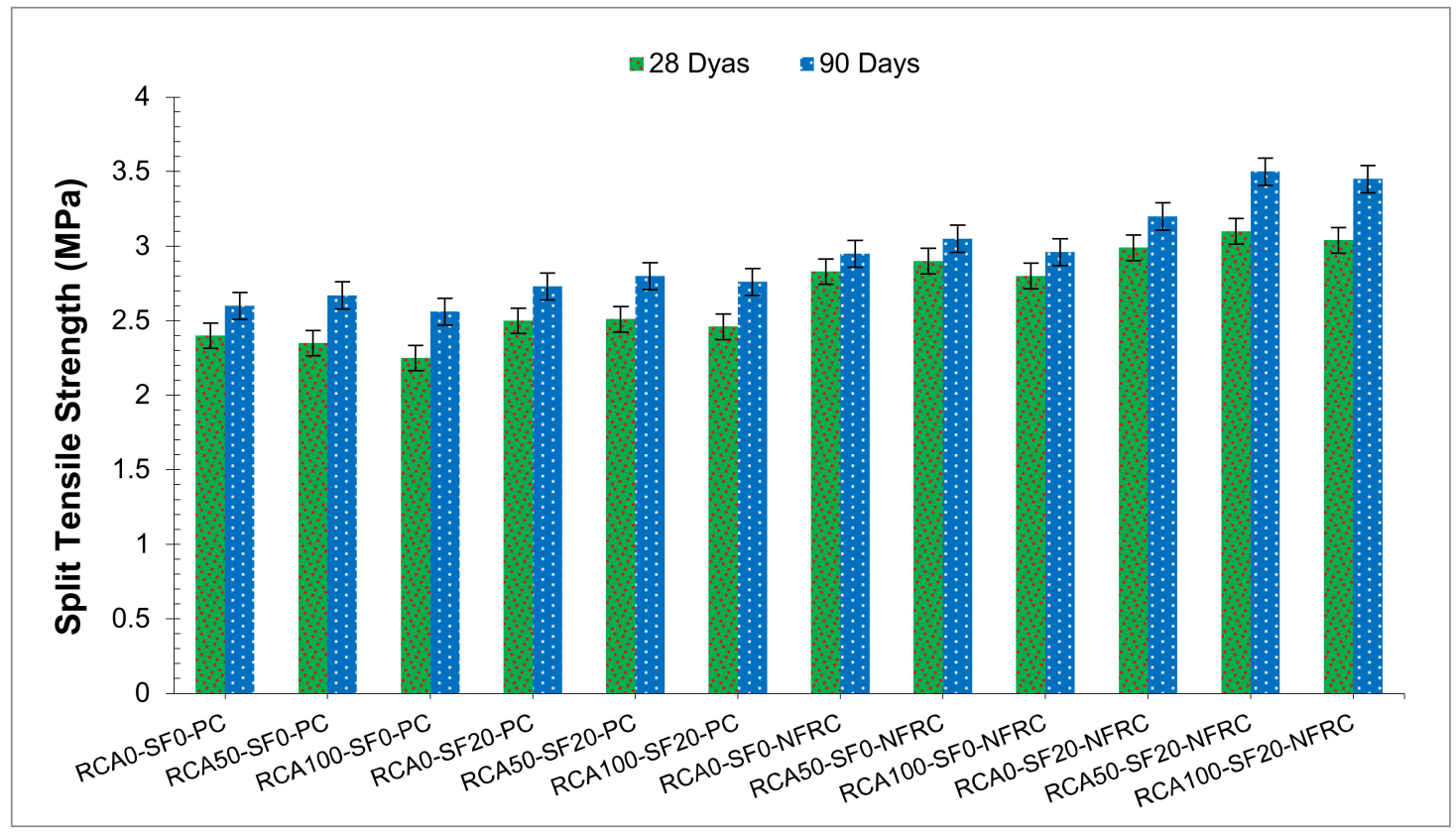

(a)

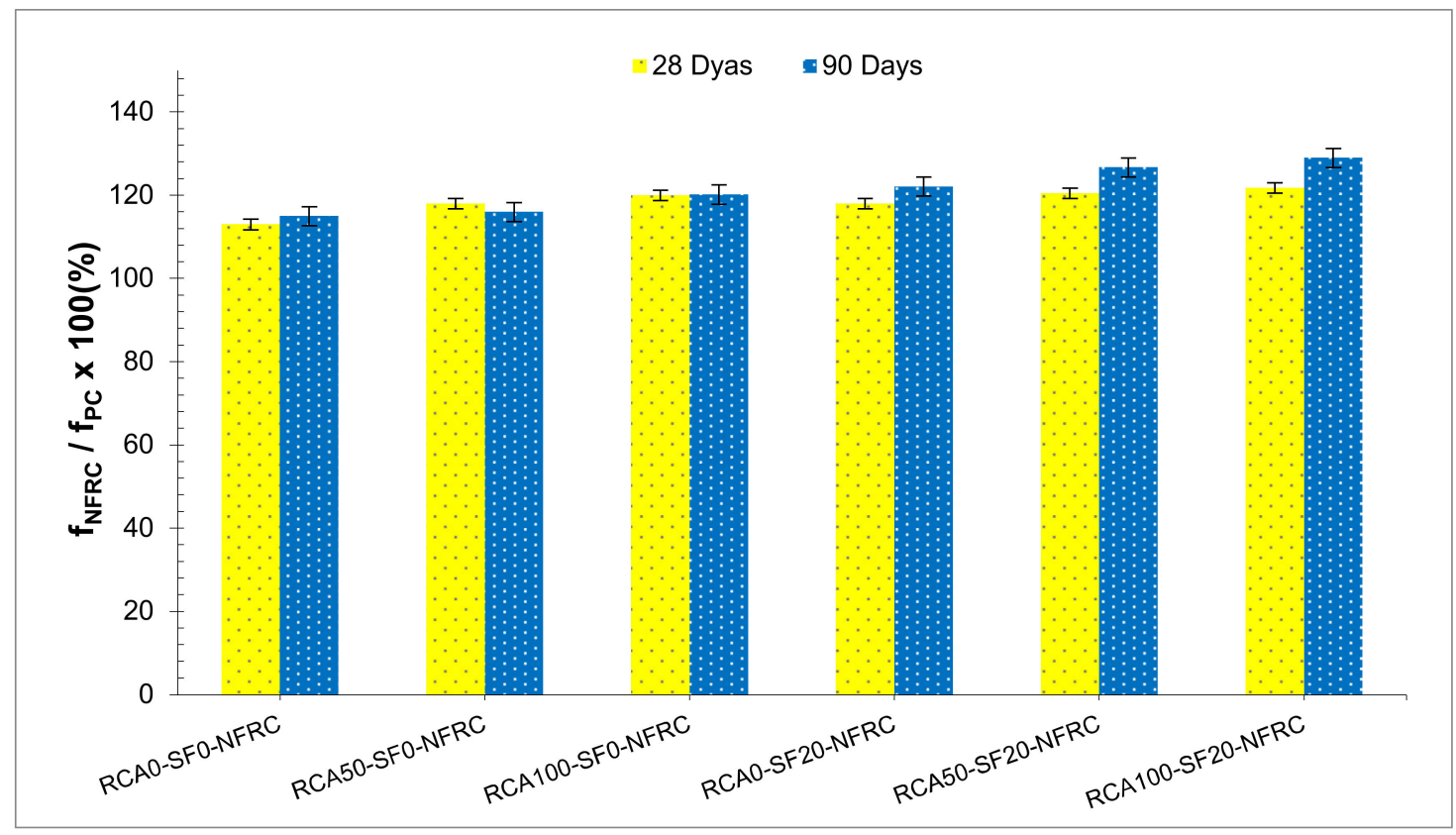

(b)

Figure 3. (a) Split Tensile Strength (b) Split Tensile Strength of Each NFRC Mix W.R.T Plain Concrete $(\mathrm{PC})$.

No major variation in split tensile strength was observed when amount of recycled concrete aggregate is increased from $0 \%$ to $100 \%$, contrasting to compressive strength, recycled concrete aggregate does not have any adverse effects on split tensile strength. This could be attributed to the difference in failure under split tensile and compression loading. In compression, recycled concrete aggregate increased dilation could increase sample lateral strain, which prompts rapid failure. Past researches [54] has revealed comparable studies. Authors in writing [26] reported that in a test of split tensile, in natural aggregate concrete failure plan passed through ITZs amid new cement paste and natural concrete aggregate demonstrating poor bond, while, in case of RAC failure plan passed well in the recycled 
concrete aggregate. ITZ failures in the case of natural aggregate concrete could need more split tensile load as compared to trans-aggregate in the case of recycled aggregate concrete. Hence, natural aggregate concrete displayed a more split tensile load as compared to recycled aggregate concrete.

For a given dose of recycled concrete aggregate, at 28 days of curing silica fume does not affect the split tensile strength majorly. At 90 days of curing, samples with silica fume did well as compared to the concrete sample with no silica fume. Silica fume ascribed more to the gaining of strength in the case of recycled aggregate concrete than natural aggregate concrete samples. By reacting at the ITZ between RCA old mortar and cement paste matrix, leads to improvement of RCA split tensile strength. It can be concluded that concrete samples having silica fume did well (4-6\%) as compared to the reference control sample (RCA0-SF0) at 90 days of curing, it can be seen in Figure 3. Recycled aggregate concrete samples having silica fume also performed better as compared to natural aggregate concrete having silica fume.

Nylon fiber leads to a notable rise in split tensile strength. Nylon fiber reinforced concrete samples have a major margin of $15 \%$ over reference control samples, it can be seen in Figure 3. Concrete samples in the presence and absence of silica fume, exhibit a prominent rise in split tensile strength. As compared to 28 days cured concrete samples, nylon fiber reinforced concrete samples display gain more split tensile strength at 90 days of curing. This could be attributed to enhanced microstructure at 90 days, which assists to form a strong bond between cement paste binder and fibers. Therefore, the concrete samples having silica fume gained more strength as compared to concrete samples with no silica fume, it can be seen in Figure 3.

Relative analysis of the split tensile strength test is displayed in Figure 4a. A relative analysis is performed on concrete samples to show that how much its performance is improved concerning the control sample. It is noted that adding nylon fiber and silica fume, (RCA) level can be exploited to enhanced performance as compared to the reference sample. For example, RCA50-SF20 and RCA50-SF20-NFRC exhibit improved performance as compared to the reference sample at 28 days of curing. Likewise, at 90 days of curing RCA100-SF20 and RCA100-SF20-NFRC also displayed improved performance as compared to the reference sample at 28 days of curing. It can be concluded that the joint utilization of silica fume, nylon fiber can assist to enhance the (RAC) performance. Statistical analysis was performed between compressive strength and split tensile strength, and a strong correlation has been observed between compressive strength and split tensile strength with a value of $\mathrm{R}^{2}$ greater than $90 \%$ as shown in Figure $4 \mathrm{~b}$.

The tensile strength of concrete is a very significant property that is considered in the design process. It makes a considerable impact on other strength properties of the structural elements such as flexural strength. Concrete is weak in tension (about $10 \%$ of concrete compressive strength) and strong in compression which results in brittle failure. This is undesirable for any structural member. Therefore, concrete needs some type of tensile reinforcement to balance its brittle conduct and enhances its tensile strength. The addition of fibers is one of the most widespread methods to improve the tensile strength of concrete. Fiber slows the cracking process by arresting the propagation of cracks and increase the energy absorption capacity of the structure. 


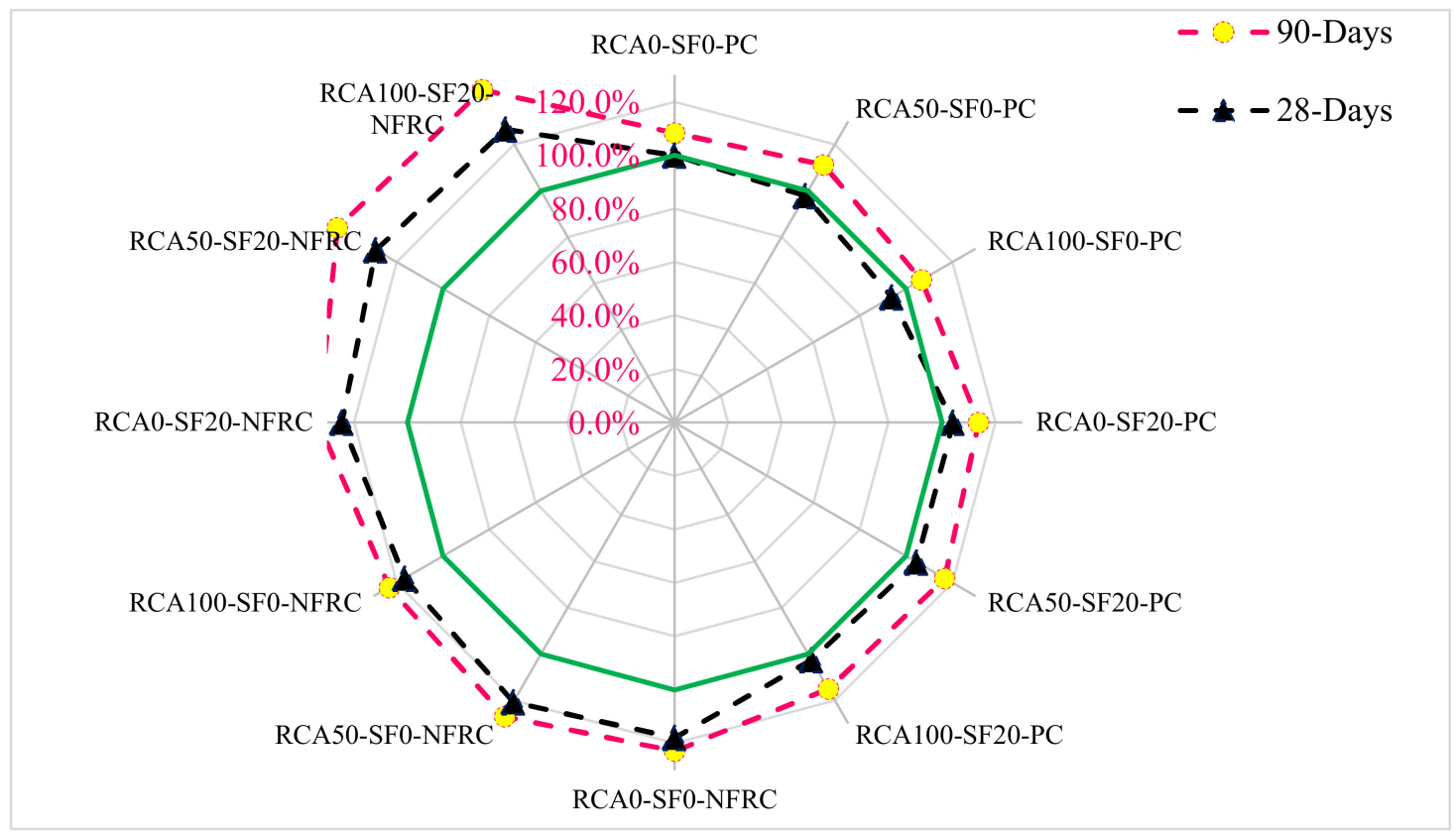

(a)

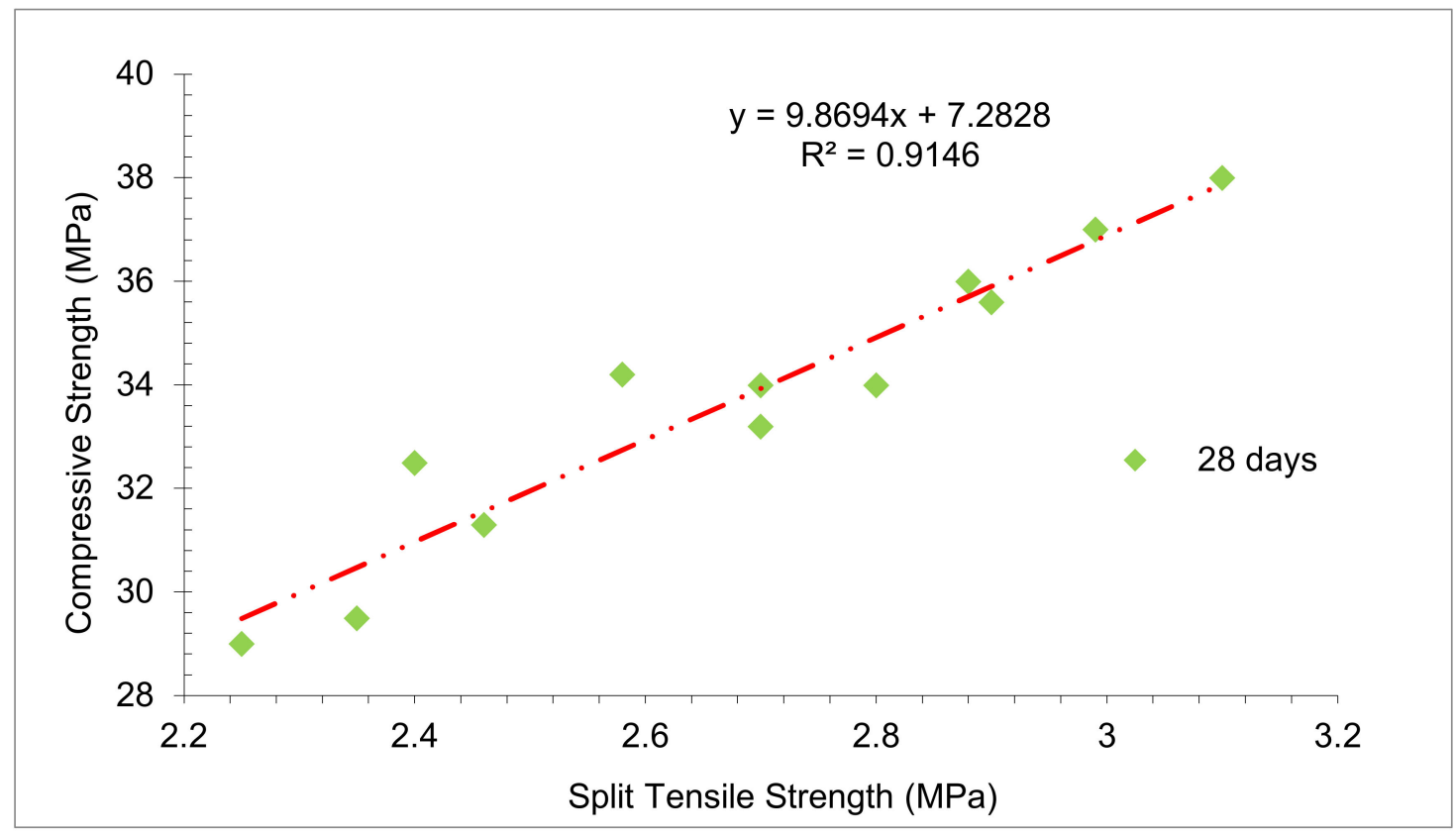

(b)

Figure 4. (a) Relative Analysis of Split Tensile Strength, (b) Correlation between Compressive and Split Tensile Strength.

In the design of reinforced concrete members, the tensile strength of the concrete is generally ignored. However, the tensile strength of concrete still has significance in terms of durability and serviceability. For example, the propagation and control of cracks are highly related to the tensile strength of concrete. Ignorance towards the tensile strength of concrete may lead to problems related to service life and durability of concrete, hence concrete must have the least tensile strength to resist all the applied load effectively. 


\subsection{Flexural Strength}

The flexural strength of all concrete samples was evaluated at 28 and 90 days of curing, as displayed in Figure 5. The flexural strength of concrete samples having silica fume displayed more improvement than cement mixed samples between 28 and 90 days of curing. Flexural strength and standard deviation and coefficient of variation of concrete sample having silica fume is moreover reference cement mixed samples at 28 and 90 days of curing, as shown in Figure 5 and Table 8.

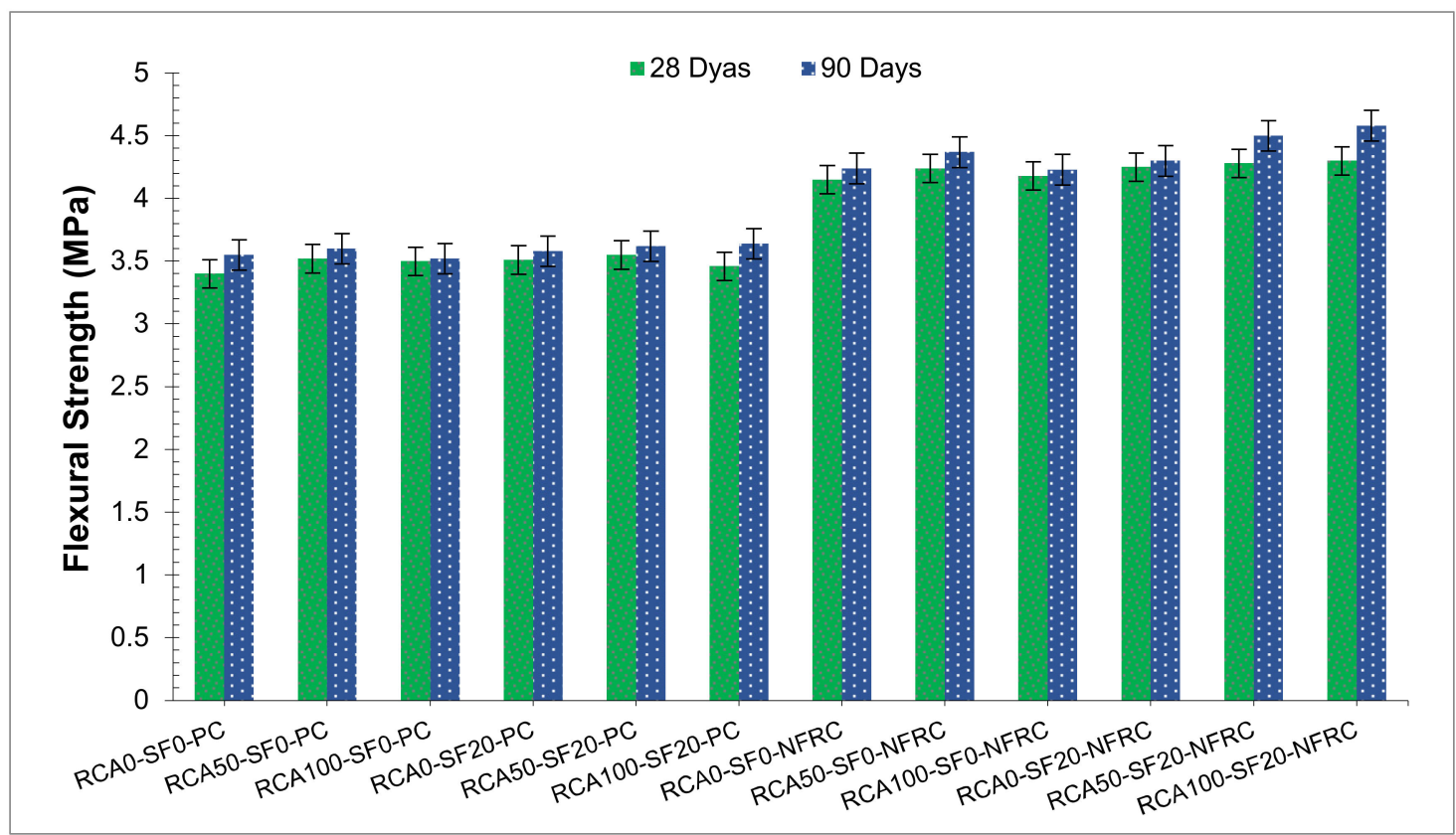

(a)

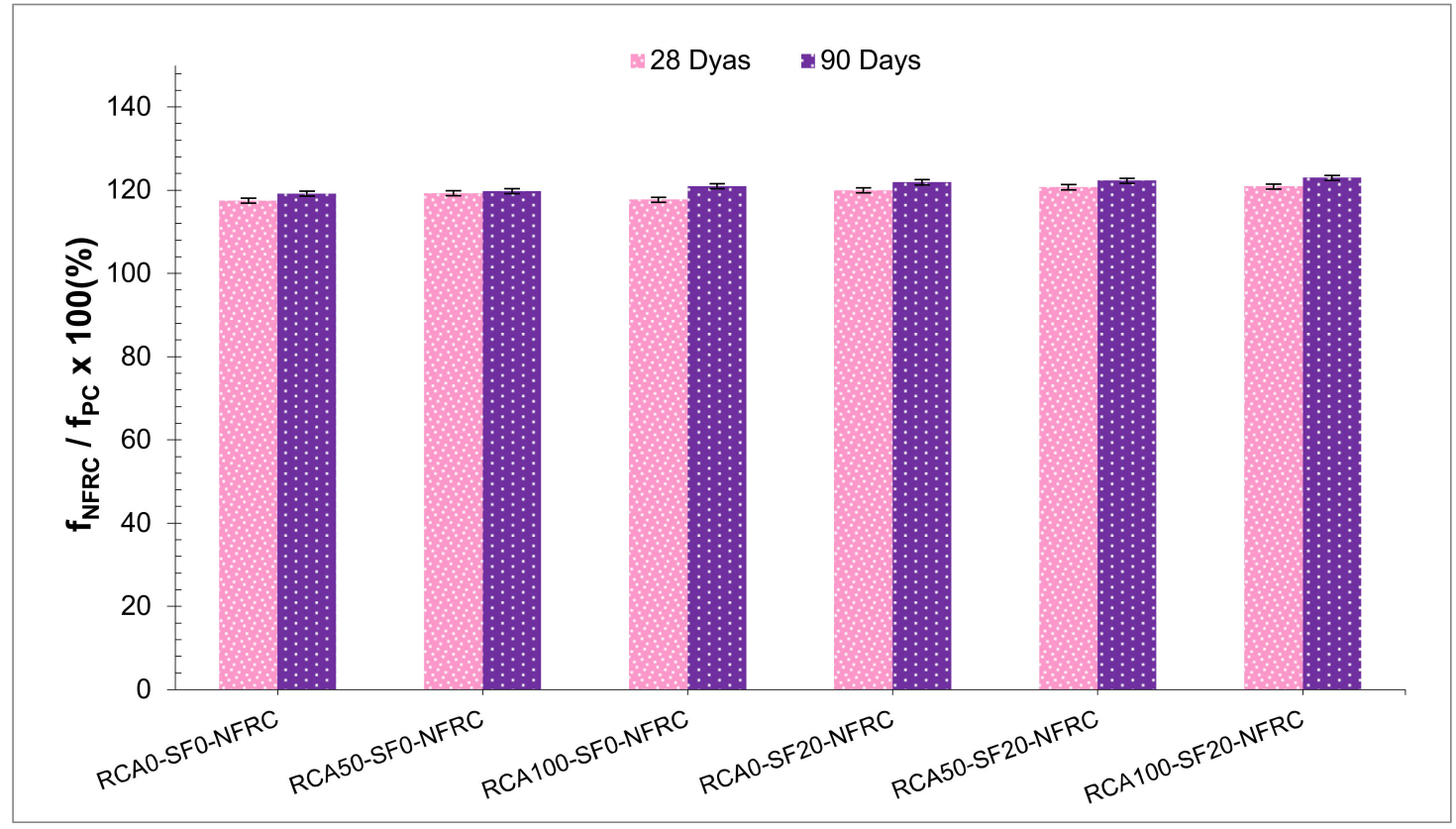

(b)

Figure 5. (a) Flexural Strength, (b) Flexural Strength of Each NFRC Mix w.r.t Plain Concrete (PC). 
Table 8. Standard Deviation and Coefficient of Variation of Flexure Strength (MPa).

\begin{tabular}{ccccc}
\hline \multirow{2}{*}{ Mix ID } & \multicolumn{2}{c}{ 28 Days } & \multicolumn{2}{c}{ 90 Days } \\
\cline { 2 - 5 } & Standard Deviation & Coefficient of Variance & Standard Deviation & Coefficient of Variance \\
\hline RCA0-SF0-PC & 0.550 & 3.568 & 0.208 & 1.366 \\
RCA50-SF0-PC & 0.737 & 4.860 & 0.436 & 2.750 \\
RCA100-SF0-PC & 0.7 & 5.691 & 0.450 & 2.847 \\
RCA0-SF20-PC & 0.929 & 5.943 & 0.351 & 2.351 \\
RCA50-SF20-PC & 0.438 & 2.803 & 0.577 & 4.570 \\
RCA100-SF20-PC & 0.346 & 2.220 & 0.458 & 2.975 \\
RCA0-SF0-NFRC & 0.945 & 6.329 & 0.754 & 4.689 \\
RCA50-SF0-NFRC & 0.404 & 3.224 & 0.450 & 2.841 \\
RCA100-SF0-NFRC & 0.655 & 4.285 & 0.680 & 4.497 \\
RCA0-SF20-NFRC & 0.490 & 3.129 & 0.503 & 3.921 \\
RCA50-SF20-NFRC & 0.305 & 1.941 & 0.358 & 2.314 \\
RCA100-SF20-NFRC & 0.828 & 5.383 & 0.929 & 5.943 \\
\hline
\end{tabular}

Nylon fiber reinforced concrete samples have a notable net gain in strength (above 19\%) in comparison to reference samples. All concrete samples of recycled concrete aggregate whether utilizing silica fume or not performed well in terms of performance in comparison to reference samples. Adding nylon fiber is more useful for flexural strength as compared to compressive and split tensile strength. Since plain concrete is weak in taking load under tension, adding nylon fibers to concrete improves its capacity notably to resist cracking due to external tensile load. Nylon fiber can competently resist tension stresses under secondary and primary stages of loading.

Nylon fiber reinforced concrete samples having silica fume exhibit more gain in flexural strength than plain concrete samples, as shown in Figure 5. In addition, nylon fiber reinforced concrete samples show better strength at 90 days of curing than at 28 days of curing. These developments in flexural strength can be attributed to the reinforcing of binder matrix with silica fume addition and age, which improves the nylon fibers bond. Nylon fiber's strong bond with the binder matrix will confirm the effectiveness of fiber strengthening in load resisting. Authors [32] have revealed that utilizing pozzolanic admixtures such as rice husk ash (RHA) in steel fiber reinforced concrete bond between binder matrix and fibers can be enhanced.

Figure 6a shows relative analysis of flexural strength of concrete samples cured at 28 and 90 days of age. A relative analysis is performed on concrete samples to show that how much its performance is improved concerning the control sample. From the figure, it can be concluded that nylon fibers reinforcement played a significant role in improving concrete flexural strength. It can be observed that the joint effect of nylon fiber and silica fume accumulation can ascribe more to the concrete mechanical strength as compared to their individual adding of each component in concrete. Such as RCA0-SF20 and RCA0-SF0NFRC samples have 4 and 19\% more flexural strength at 90 days of curing as compared to reference concrete samples. While RCA0-SF20-NFRC has $26 \%$ more flexural strength as compared to the reference sample. Hence, the effect of joint utilization of silica fume and nylon fibers leads to more strength gain in flexural capacity.

Statistical analysis was performed between compressive strength and flexure strength, and a strong correlation has been observed between compressive strength and flexure strength with a value of $R^{2}$ greater than $90 \%$ Figure $6 \mathrm{~b}$. 


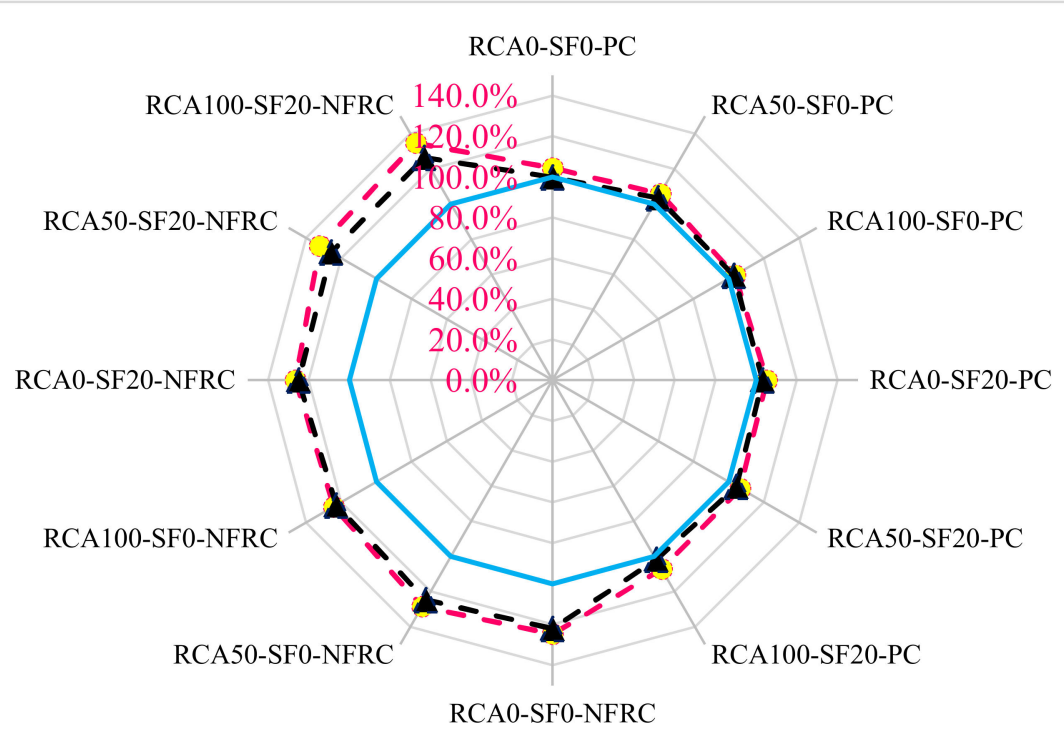

-90 -Days

$-\ldots-28$-Days

(a)

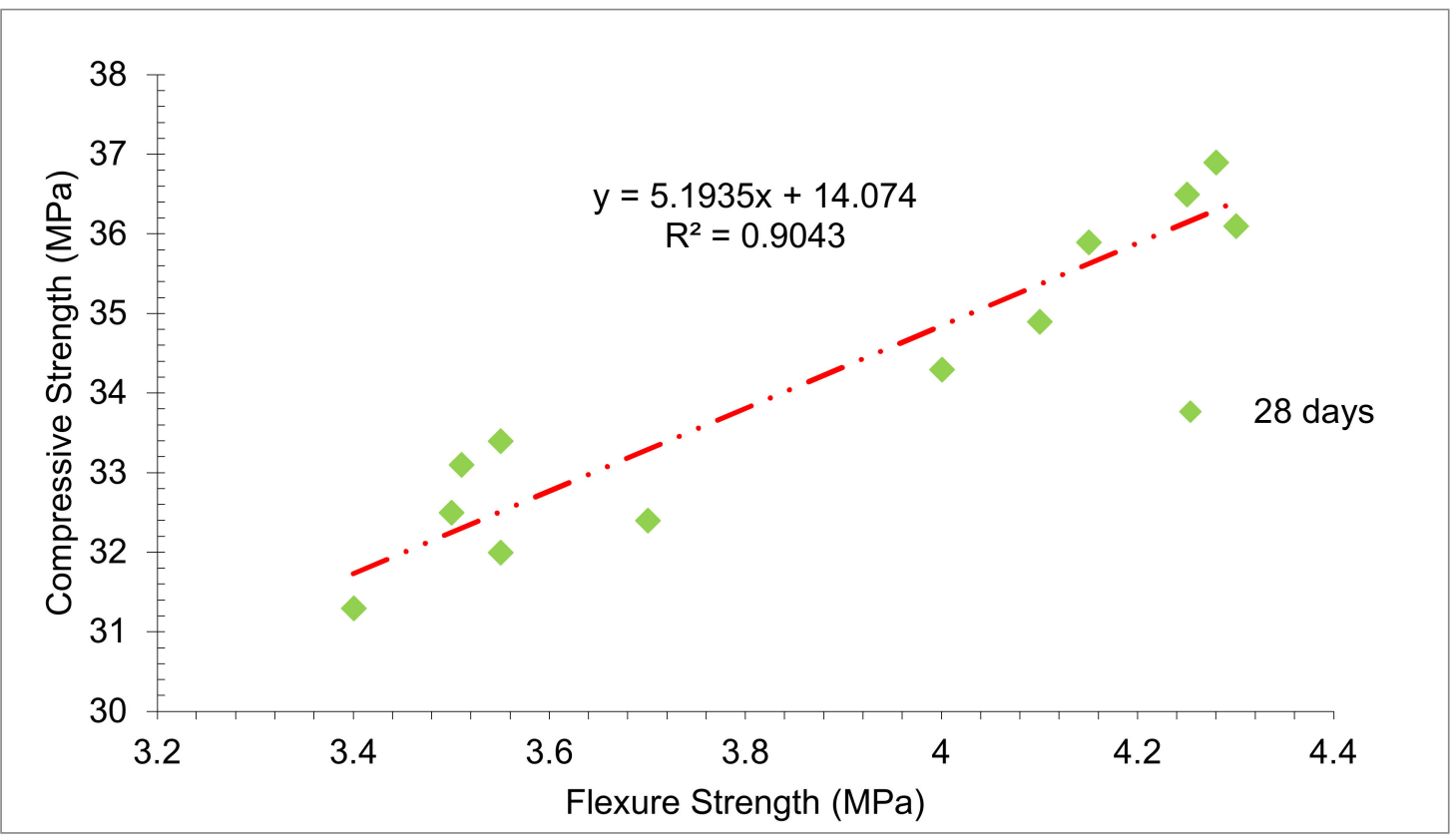

(b)

Figure 6. (a) Relative Analysis of Flexure Strength, (b) Correlation between Compressive and Flexure strength.

\subsection{Acid Resistance Test}

A lot of cement's reaction elements have alkalinity specially $\mathrm{C}-\mathrm{H}$ (which has a $\mathrm{pH}$ of more than 12). Thus, concrete made from Portland cement is highly susceptible to acid. There are various types of strong acid, some of them are sulfuric acid $\left(\mathrm{H}_{2} \mathrm{SO}_{4}\right)$, acetic acid, hydrochloric acid, and nitric acid. Many of these acids are present in wastewater from industries. Because of the very low value of $\mathrm{pH}$, Sulfuric acid $\left(\mathrm{H}_{2} \mathrm{SO}_{4}\right)$ is the most damaging and hostile acid, that when reacts with $\mathrm{C}-\mathrm{H}$, makes $\left(\mathrm{CaSO}_{4}\right)$ calcium sulfate which is a type of salt, which results in fast concrete degradation. In the present research, samples were placed in a $5 \%$ solution of sulfuric acid $\left(\mathrm{H}_{2} \mathrm{SO}_{4}\right)$ and loss of mass as the degree of 
degradation for each concrete sample for $28,56,90$, and 120 days. The outcome of this test is displayed in Figure 7. The test outcome exhibits that concrete samples utilizing recycled concrete aggregate degrade very quickly as compared to samples having no recycled concrete aggregate. Recycled concrete aggregate has more quantity of $\mathrm{C}-\mathrm{H}$ (exist in old mortar) and has high porosity as compared to natural concrete aggregate. Therefore, one of the potential approaches to enhance recycled aggregate concrete susceptibility against acid is by decreasing its amount in concrete. The utilization of silica fume is useful to susceptibility against acid at all ages of concrete. Silica fume addition decreases the calcium oxide quantity of binder, which prompts the low making of $\mathrm{C}-\mathrm{H}$ as in comparison to samples having no silica fume. Besides, free $\mathrm{C}-\mathrm{H}$ is consumed in pozzolanic reaction with silica fume aluminosilicate particles which produces chemical resistant and denser C-S-H [54]. Silica fume also enhances concrete ability against penetration of harmful elements, which causes decelerating the development of degradation of concrete samples. Enhancement in concrete susceptibility against acid has been revealed by [55] when supplementary materials with low calcium such as bentonite and RHA [32] are utilized as a cement substitute.

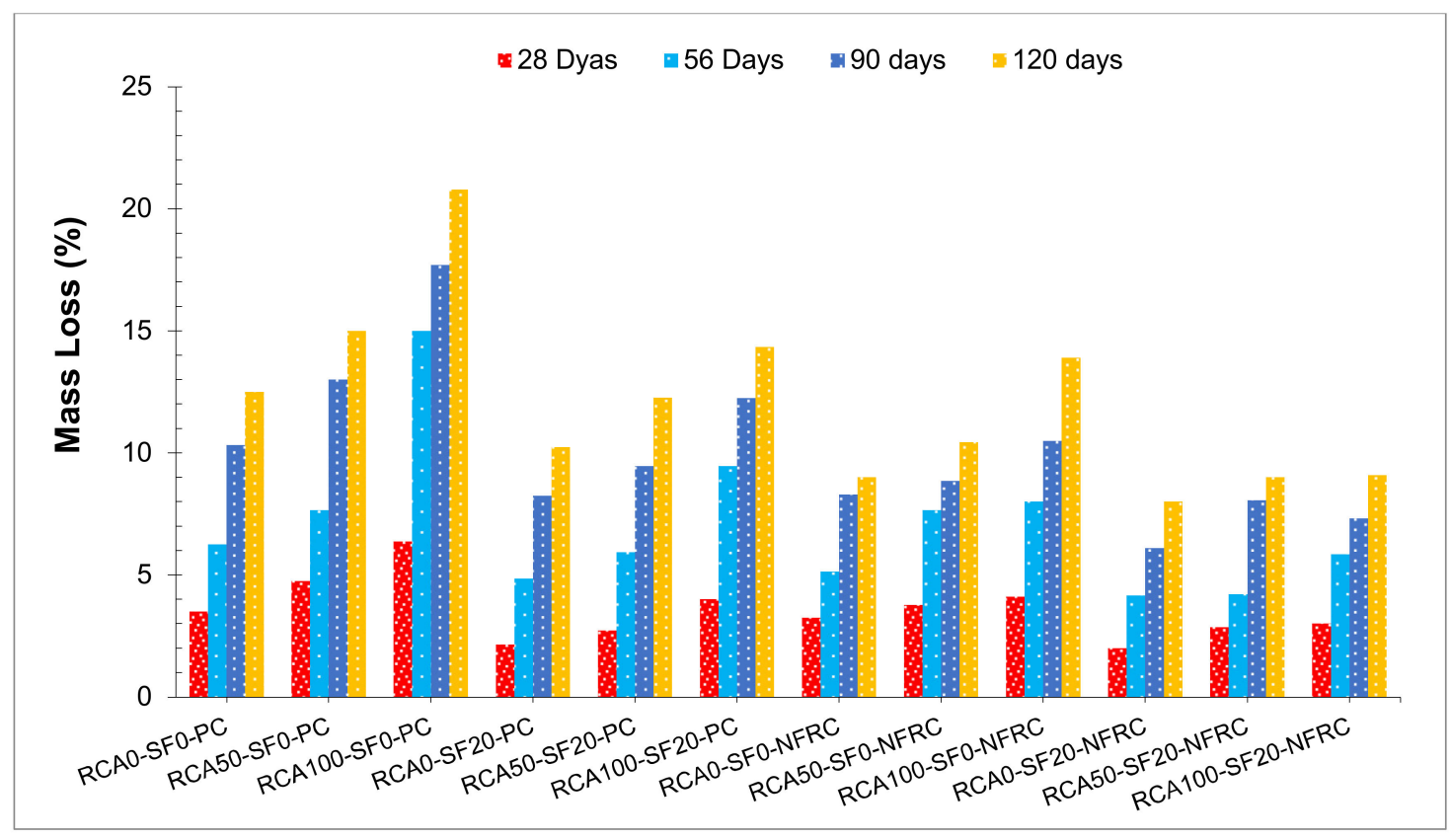

Figure 7. Concrete Mass Loss Due to Sulfuric Acid (\%).

Nylon fiber reinforced concrete samples exhibit that they are less susceptible to acid i.e., NFRC improves concrete capacity against acid attack as compared to plain concrete samples. Nylon fibers produce microchannels [56] that can assist in quicker penetration of acid to the microstructure, but on the positive side, fibers can assist in sustaining binder matrix integrity. Under acid exposure, the utilization of fibers is best known to decrease the degradation of mass and strength because [26] fiber's assist in governing the expansion when gypsum and ettringite are formed. The utilization of silica fume into nylon fiber reinforced concrete samples also helps concrete with less vulnerability against acid. It can be decided that concrete utilizing recycled concrete aggregate, its resistance against acid can be improved by using nylon fibers, silica fume, or both.

\subsection{Water Absorption}

Concrete with high permeability can assist chemicals that are harmful to pierce and react with cement-based material ingredients to alter its properties. Water absorption of concrete samples was measured at 28 and 90 days of curing, as shown in Figure 8. 


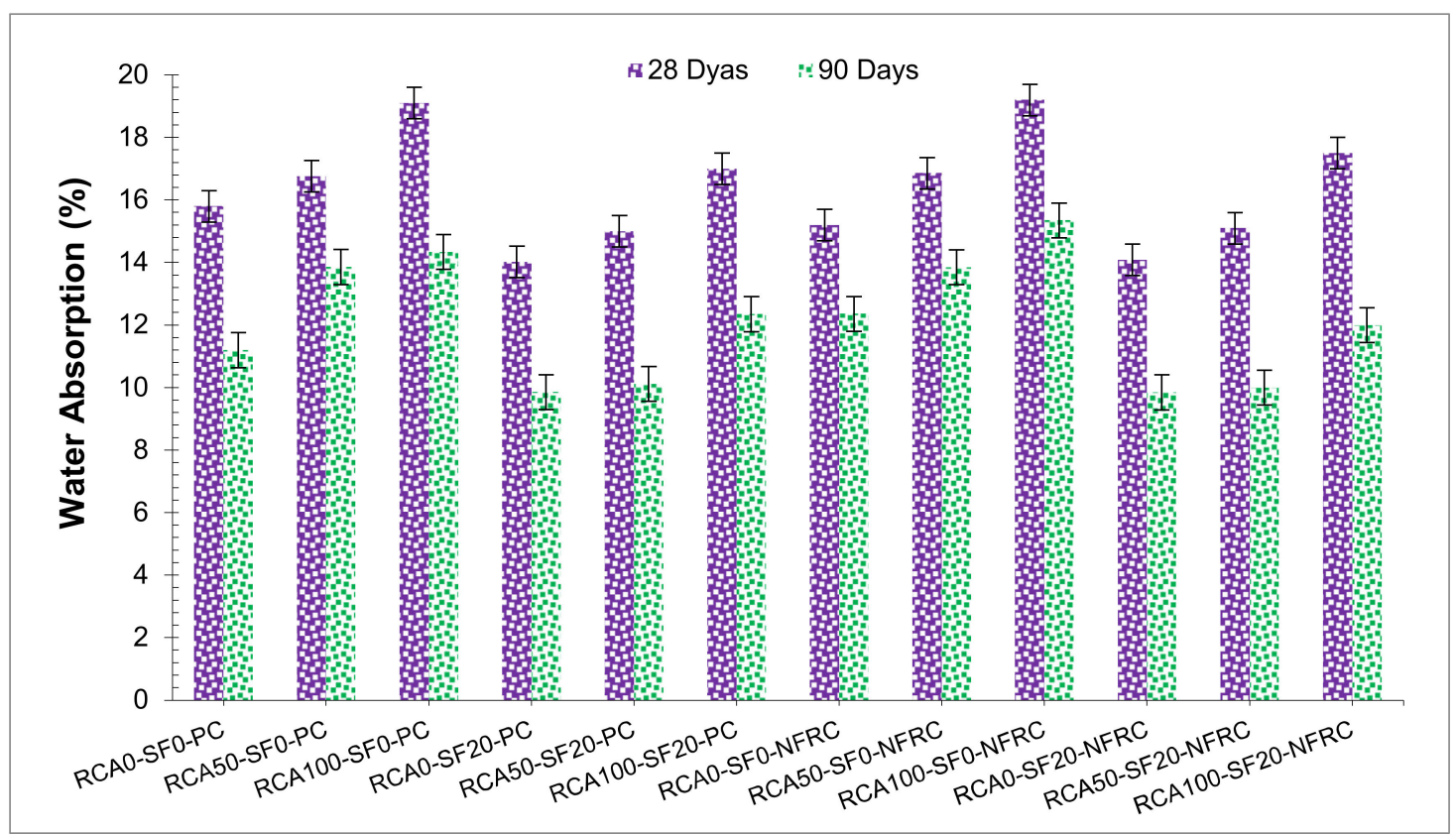

Figure 8. Water Absorption of Concrete.

It is observed that water absorption is affected negatively by increasing the doses of recycled concrete aggregate. Water absorption is increased by $8 \%$, at $50 \%$ recycled concrete aggregate and $22 \%$ at $100 \%$ recycled concrete aggregate. This is attributed to the existence of adhered mortar which had low density and a lot of ITZs in the recycled concrete aggregate which assists easy water penetration. Adding silica fume assists in decreasing the concrete water absorption for a given dose of recycled concrete aggregate. Water decreases by $10 \%$ when silica fume is utilized as a partial substitute for cement. This can be attributed to the filler effect of the silica fume particles. In addition, silica fume consumes $\mathrm{C}-\mathrm{H}$ in pozzolanic reaction to form C-S-H gel, which could also reduce the microchannels connectivity within the binder matrix. Silica fume also assists in decreasing the water absorption of a concrete sample utilizing recycled concrete aggregate-such as RCA50-SF20 exhibits water absorption similar to the reference sample at 28 and 90 days of curing. However, a considerable decrease is also observed in the water absorption of concrete with $100 \%$ recycled concrete aggregate.

The utilization of nylon fibers increases water absorption by 3-6\%. Nylon fiber reinforced concrete samples have marginally more water absorption as compared to plain concrete samples. This could be attributed to enhanced microchannels connectivity within the binder matrix and concrete outer surface. Researches have also revealed that concrete [11] sorptivity, and water absorption [32] increases with adding fibers because of the increase in microchannel length in the microstructure. Adding silica fume not only decreases plain concrete water absorption but also reduces nylon fiber-reinforced concrete water absorption. Such as, RCA0-SF20-NFRC has low water absorption as compared to RCA0-SF0-PC and RCA0-SF0-NFRC mixes. Fibers enhanced bond because of silica fume adding could also assist in decreasing the pore volume connectivity which decreases concrete water absorption capacity. It could be settled that adding silica fume can recompense for durability loss because of the utilization of both nylon fibers and recycled concrete aggregate.

\subsection{Chloride Penetration Test}

Chloride penetration can cause steel bars corrosion in RCC buildings; therefore, studying concrete susceptibility against chloride penetration is very necessary from the life span and serviceability of concrete buildings in mediums bearing chloride such as soils, seawater, etc. Values of the chloride penetration of concrete samples are presented in Figure 9. An 
increasing dose of recycled concrete aggregate also increases chloride penetration. Recycled concrete aggregate higher capacity for water absorption than natural concrete aggregate made it easy for the solution to penetrate having $\left(\mathrm{Cl}^{-}\right)$. Moreover, utilization of silica fume is helping to improve durability against chloride penetration, RCA0-SF20 sample showed $18 \%$ and $29 \%$ less chloride penetration than the reference sample at 28 and 90 days of curing. Authors in the study [57] defined that silica fume decreased the size of the pore in concrete enhances the resistance to chloride penetration, it is because adding silica fume slows the movement of chloride ions. Resistance to chloride penetration is enhanced because of an increase in the quantity of alumina in cement [58]. This causes the formation of a dense C-S-H structure and $\mathrm{C}_{3} \mathrm{~A}$ which could bind the chloride ions [57]. Silica fume also enhances chloride penetration of concrete samples having recycled concrete aggregate. Concrete samples with $20 \%$ silica fume and $50 \%$ recycled concrete aggregate showed similar chloride penetration as reference samples.

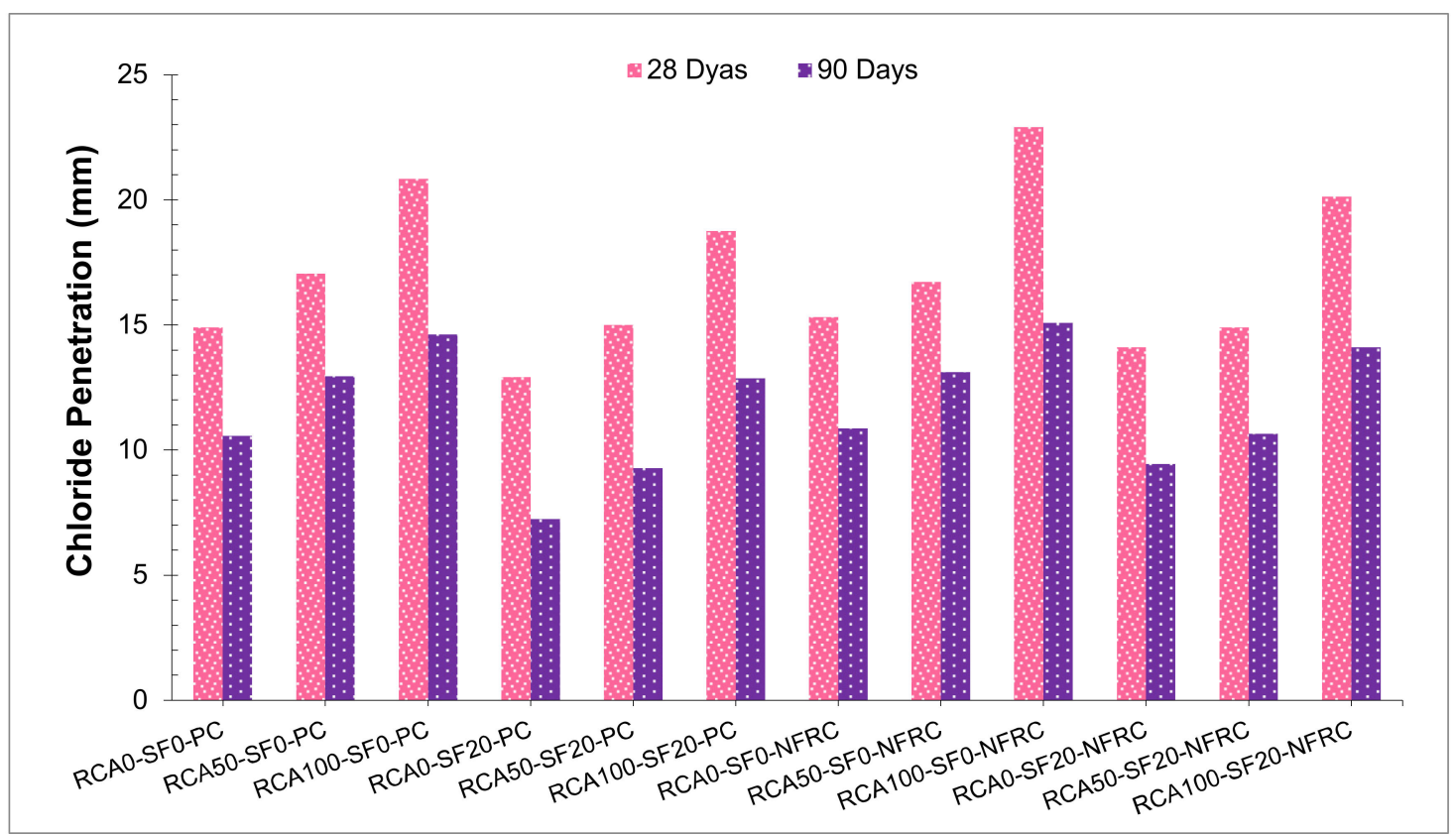

Figure 9. Chloride Penetration of Concrete (mm).

Past researches have similarly revealed the detrimental effect of fibers such as (polypropylene, steel) [59] on concrete chloride permeability. The outcomes of chloride penetration are similar to water absorption results. Since durability performance relies upon concrete accessible porosity. Adding silica fume is useful to nylon fiber reinforced concrete resistance against chloride penetration, NFRC samples which had 50\% recycled concrete aggregate and $20 \%$ silica fume showed chloride penetration as similar to the reference sample because of silica fume. It can be concluded, to sustain concrete durability similar to plain concrete samples, it is necessary to use nylon fibers with SCMs [60].

\section{Life Cycle Assessment and Sustainability Performance}

As concrete is few of the major material utilized in most the construction industry, a lot of studies are performed in this domain on different sorts of concrete for various purposes for instance enhancing the microstructure, mechanical and physical characteristics, durability, sustainability and life cycle. At the present time, most of the researchers [3,54] are performing their finest to obtain explore the best answer so they could recycle waste materials, especially in construction and concrete sector [61-63], in order to contribute to the environmental problems. They have $[8,64,65]$ made significant strides and based on their findings, recycled aggregate concrete or green concrete can be measured as an appropriate answer in this context. The utilization of recycled concrete aggregate as coarse 
aggregate in concrete preserves granite stone, which is one of the fastest depleting natural materials but also offers a solution for the discarding of construction and infrastructure waste. When silica fume is added to concrete, the depletion of limestone, which is a raw ingredient needed for cement manufacturing is reduced, and therefore, the sustainability feature in the manufacturing of concrete is improved. This will significantly lower the outflow of carbon dioxide, nitrogen dioxide, and other harmful gases to the environment and also assist in limestone preservation. It can be noted that utilization of nylon fibers improved the concrete mechanical performance made with the composite addition of silica fume and recycled aggregate and this concrete could be also used for structural applications. Therefore, the concrete industry can be made sustainable by adopting the method applied in the current study by the joint incorporation of recycled aggregate, silica fume, and nylon fibers.

\section{Cost Benefit Analysis}

Recycled aggregate, and silica fume are both waste products, when they are disposed in landfills it leads to severe land pollution and degrade surrounding atmosphere. To procure these waste products, it had little to no cost excepting for transport charges. Table 9 shows cost benefit analysis of different ingredient of concrete used in this study. Recycled aggregates were procured from the crushed concrete, while silica fume and nylon fibers were obtained from the market place. The material rates displayed in Table 9 are from the market place. Among the whole mixes, RCA50-SF20-NFRC was the optimal mix because it had more improved performance in both durability and strength. The reason that cost of recycled aggregate concrete was a little bit more than natural aggregate concrete, is that both silica fume and nylon fibers were ordered from a retailer, and it also had transportation charges. However, this minor increase in cost can be justified by the enhanced concrete with improved mechanical strength and durability performance.

Table 9. Cost Benefit Analysis.

\begin{tabular}{ccccc}
\hline Mix ID & Cost (Rs) Per Cum & Cost (Rs) Per Cum & Cost (Rs) Per Cum & Cost (Rs) Per Cum \\
\hline & Natural aggregate concrete & & Recycled aggregate concrete & RAC + SF + NFs \\
RCA0-SF0-PC & 3000 & RAC & RAC + SF & 3100 \\
RCA50-SF0-PC & 3000 & 2500 & 2800 & 3100 \\
RCA100-SF0-PC & 3000 & 2500 & 2800 & 3100 \\
RCA0-SF20-PC & 3000 & 2500 & 2800 & 3100 \\
RCA50-SF20-PC & 3000 & 2500 & 2800 & 3100 \\
RCA100-SF20-PC & 3000 & 2500 & 2800 & 3100 \\
RCA0-SF0-NFRC & 3000 & 2500 & 2800 & 3100 \\
RCA50-SF0-NFRC & 3000 & 2500 & 2800 & 3100 \\
RCA100-SF0-NFRC & 3000 & 2500 & 2800 & 3100 \\
RCA0-SF20-NFRC & 3000 & 2500 & 2800 & 3100 \\
RCA50-SF20-NFRC & 3000 & 2500 & 2800 & 3100 \\
RCA100-SF20-NFRC & 3000 & 2500 & 2800 & 3100 \\
\hline
\end{tabular}

\section{Conclusions}

In the present research, the synergic effect of silica fume SF and nylon fiber NF was studied on the mechanical characteristics and durability aspects of concrete utilizing recycled concrete aggregate RCA. The following conclusions are obtained from the study.

1. RCA concrete major issue is that it has poor mechanical and durability performance could be solved by joint adding of silica fume SF and nylon fibers. Optimum mix regarding mechanical behavior and durability performance and sustainability of RCA concrete was obtained at 50\% RCA, $0.5 \%$ nylon fibers, and $20 \%$ silica fume.

2. Adding $20 \%$ silica fume at cement substitute enhanced the later strength of both natural aggregate concrete and recycled concrete aggregate utilizing mixes. Silica 
fume ascribed more to the development of durability and strength in the concrete sample having recycled concrete aggregate.

3. Silica fume reduced chloride penetration, water absorption, and recycled aggregate concrete degradation in the solution of acid. Silica fume also enhances nylon fiber reinforced concrete penetration resistance against chloride penetration and water absorption.

4. Nylon fiber improved the mechanical performance of NAC and RCA incorporating mixes up to $26 \%$. Nylon fiber was useful for flexural and split tensile strength as compared to compressive strength. Nylon fiber increased chloride penetration and water absorption by $18 \%$ and $8 \%$ respectively but also improved the resistance against acid attack.

5. At a given dose of recycled concrete aggregate, nylon fiber reinforced concrete exhibited marginally more chloride penetration and water absorption than plain concrete but resistance against acid attack was more than plain concrete.

6. Silica fume utilizing nylon fiber reinforced concrete samples displayed more gain in mechanical strength as compared to mixes with no silica fume.

7. With the utilization of nylon fibers in concrete, nylon fibers played a significant role in concrete as crack arrestors, lowering the permeability, reducing the dispersion of cracks, and also improving the strength of concrete.

8. From cost benefit analysis, the small extra cost can be justified as in case of using fibers, RCA and silica fume, this small extra cost improved the concrete performance significantly with better strength and durability in comparison to the normal concrete.

9. Reusing waste materials such as silica fume and recycled aggregate can not only help in preserving the natural deposits of limestone, but it will also add value to the waste materials when it is reused, which promotes circular economy and also helps the environment greatly.

The current research showed that the waste/recycled materials such as (silica fume, recycled aggregate) can be effectively utilized in the nylon fiber reinforced concrete, the concrete with waste materials showed improved performance but it was also cost effective, which comes to conclusion that we can help preserve our natural materials from being overly used in construction industry by using these waste/recycled materials, which will bring us one step close to achieving sustainability.

Author Contributions: Conceptualization-J.A. and O.Z., writing—original draft preparation, O.Z., resources-C.L.-C.P., R.M.-G. and F.L.-G. All authors have read and agreed to the published version of the manuscript.

Funding: No funding was provided by anyone for the study.

Institutional Review Board Statement: Not applicable.

Informed Consent Statement: Not applicable.

Data Availability Statement: Data are available by request from the corresponding author.

Conflicts of Interest: The authors declare no conflict of interest.

\section{References}

1. Jaillon, L.; Poon, C.S. Sustainable construction aspects of using prefabrication in dense urban environment: A Hong Kong case study. Constr. Manag. Econ. 2008, 26, 953-966. [CrossRef]

2. Akhtar, A.; Sarmah, A.K. Construction and demolition waste generation and properties of recycled aggregate concrete: A global perspective. J. Clean. Prod. 2018, 186, 262-281. [CrossRef]

3. Ahmad, J.; Zaid, O.; Shahzaib, M.; Abdullah, M.U.; Ullah, A.; Ullah, R. Mechanical properties of sustainable concrete modified by adding marble slurry as cement substitution. AIMS Mater. Sci. 2021, 8, 343-358. [CrossRef]

4. $\mathrm{Li}, \mathrm{X}$. Recycling and reuse of waste concrete in China: Part II. Structural behaviour of recycled aggregate concrete and engineering applications. Resour. Conserv. Recycl. 2009, 53, 107-112. [CrossRef]

5. Ober, J.A. Mineral Commodity Summaries 2016; US Geological Survey, 2016. Available online: https://pubs.er.usgs.gov/ publication/70170140 (accessed on 5 November 2021). 
6. Zaid, O.; Ahmad, J.; Siddique, M.S.; Aslam, F.; Alabduljabbar, H.; Khedher, K.M. A step towards sustainable glass fiber reinforced concrete utilizing silica fume and waste coconut shell aggregate. Sci. Rep. 2021, 11, 12822. [CrossRef]

7. Zaid, O.; Zamir Hashmi, S.R.; Aslam, F.; Alabduljabbar, H. Experimental Study on Mechanical Performance of Recycled Fine Aggregate Concrete Reinforced with Discarded Carbon Fibers. Front. Mater. 2021, 8, 481. [CrossRef]

8. Zaid, O.; Aslam, F.; Alabduljabbar, H. To evaluate the performance of waste marble powder and wheat straw ash in steel fiber reinforced concrete. Struct. Concr. 2021, in press. [CrossRef]

9. Kurad, R.; Silvestre, J.D.; de Brito, J.; Ahmed, H. Effect of incorporation of high volume of recycled concrete aggregates and fly ash on the strength and global warming potential of concrete. J. Clean. Prod. 2017, 166, 485-502. [CrossRef]

10. Chu, S.H.; Poon, C.S.; Lam, C.S.; Li, L. Effect of natural and recycled aggregate packing on properties of concrete blocks. Constr. Build. Mater. 2021, 278, 122247. [CrossRef]

11. Ali, B.; Qureshi, L.A.; Raza, A.; Nawaz, M.A.; Rehman, S.U.; Rashid, M.U. Influence of glass fibers on mechanical properties of concrete with recycled coarse aggregates. Civ. Eng. J. 2019, 5, 1007-1019. [CrossRef]

12. Ou, Y.-C.; Tsai, M.-S.; Liu, K.-Y.; Chang, K.-C. Compressive behavior of steel-fiber-reinforced concrete with a high reinforcing index. J. Mater. Civ. Eng. 2012, 24, 207-215. [CrossRef]

13. Kurda, R.; de Brito, J.; Silvestre, J.D. Water absorption and electrical resistivity of concrete with recycled concrete aggregates and fly ash. Cem. Concr. Compos. 2019, 95, 169-182. [CrossRef]

14. Sorelli, L.G.; Meda, A.; Plizzari, G.A. Steel fiber concrete slabs on ground: A structural matter. ACI Struct. J. 2006, $103,551$.

15. Zheng, Y.; Wu, X.; He, G.; Shang, Q.; Xu, J.; Sun, Y. Mechanical Properties of Steel Fiber-Reinforced Concrete by Vibratory Mixing Technology. Adv. Civ. Eng. 2018, 2018, 9025715. [CrossRef]

16. Vairagade, V.S.; Kene, K.S. Introduction to steel fiber reinforced concrete on engineering performance of concrete. Int. J. Sci. Technol. Res. 2012, 1, 141.

17. Usman, M.; Farooq, S.H.; Umair, M.; Hanif, A. Axial compressive behavior of confined steel fiber reinforced high strength concrete. Constr. Build. Mater. 2020, 230, 117043. [CrossRef]

18. Sangeeta, K.N. A Review study on use of Steel Fiber as Reinforcement Material with Concrete. IOSR J. Mech. Civ. Eng. 2015, 12, 95-98.

19. Mohod, M.V. Performance of steel fiber reinforced concrete. Int. J. Eng. Sci. 2012, 1, 8-17.

20. Berrocal, C.G.; Lundgren, K.; Löfgren, I. Corrosion of steel bars embedded in fibre reinforced concrete under chloride attack: State of the art. Cem. Concr. Res. 2016, 80, 69-85. [CrossRef]

21. Martínez-Barrera, G.; Menchaca-Campos, C.; Hernández-López, S.; Vigueras-Santiago, E.; Brostow, W. Concrete reinforced with irradiated nylon fibers. J. Mater. Res. 2006, 21, 484-491. [CrossRef]

22. Hossain, M.A.; Rahman, M.M.; Morshed, A.Z.; Haque, S.K.M. Investigation of the effect of nylon fiber in concrete rehabilitation In Proceedings of the 1st International Conference on Civil Engineering for Sustainable Development (ICCESD-2012), Khulna, Bangladesh, 2-3 March 2012.

23. Saxena, J.; Saxena, A. Enhancement the strength of conventional concrete by using nylon fibre. Int. J. Eng. Sci. 2015, 5, 56-59.

24. Xenopoulos, A.; Clark, E.S. Nylon Plastics Handbook; Kohan, M.I., Ed.; Elsevier: Amsterdam, The Netherlands, 1995 ; Volume 108.

25. Beyerlein, A. Nylon Fiber Facts. Clemson Univ. com/nylene_pdfs/clemson_university_report.pdf). Interviews with Anette Timmer-Larsen, Dir. Mark. Commun. C2C, Rudi Daelmans, Dir. Sustain. Willem Stas, Dir. Oper. Available online: https://journals.sagepub.com/ doi/full/10.1177/15589250211062833 (accessed on 5 November 2021).

26. Ahmad, J.; Aslam, F.; Zaid, O.; Alyousef, R.; Alabduljabbar, H.; Manan, A. Self-Fibers Compacting Concrete Properties Reinforced with Propylene Fibers. Sci. Eng. Compos. Mater. 2021, 28, 64-72. [CrossRef]

27. Weber, E.H.; Clingerman, M.L.; King, J.A. Thermally conductive nylon 6, 6 and polycarbonate based resins. II. Modeling. J. Appl. Polym. Sci. 2003, 88, 123-130. [CrossRef]

28. Lee, G.; Han, D.; Han, M.-C.; Han, C.-G.; Son, H.-J. Combining polypropylene and nylon fibers to optimize fiber addition for spalling protection of high-strength concrete. Constr. Build. Mater. 2012, 34, 313-320. [CrossRef]

29. Dong, J.F.; Wang, Q.Y.; Guan, Z.W. Material properties of basalt fibre reinforced concrete made with recycled earthquake waste. Constr. Build. Mater. 2017, 130, 241-251. [CrossRef]

30. Akça, K.R.; Çakır, Ö.; İpek, M. Properties of polypropylene fiber reinforced concrete using recycled aggregates. Constr. Build. Mater. 2015, 98, 620-630. [CrossRef]

31. Ahmad, J.; Al-Dala'ien, R.N.S.; Manan, A.; Zaid, O.; Ahmad, M. Evaluating the effects of flexure cracking behaviour of beam reinforced with steel fibres from environment affect. J. Green Eng. 2020, 10, 4998-5016.

32. Koushkbaghi, M.; Kazemi, M.J.; Mosavi, H.; Mohseni, E. Acid resistance and durability properties of steel fiber-reinforced concrete incorporating rice husk ash and recycled aggregate. Constr. Build. Mater. 2019, 202, 266-275. [CrossRef]

33. Chu, S.H.; Li, L.G.; Kwan, A.K.H. Fibre factors governing the fresh and hardened properties of steel FRC. Constr. Build. Mater. 2018, 186, 1228-1238. [CrossRef]

34. Ali, B.; Qureshi, L.A. Combined effect of fly ash and glass fibers on mechanical performance of concrete. NED Univ. J. Res. 2018, 15, 91-100.

35. Barbuta, M.; Bucur, R.; Serbanoiu, A.A.; Scutarasu, S.; Burlacu, A. Combined effect of fly ash and fibers on properties of cement concrete. Procedia Eng. 2017, 181, 280-284. [CrossRef] 
36. Fallah, S.; Nematzadeh, M. Mechanical properties and durability of high-strength concrete containing macro-polymeric and polypropylene fibers with nano-silica and silica fume. Constr. Build. Mater. 2017, 132, 170-187. [CrossRef]

37. Xie, J.; Huang, L.; Guo, Y.; Li, Z.; Fang, C.; Li, L.; Wang, J. Experimental study on the compressive and flexural behaviour of recycled aggregate concrete modified with silica fume and fibres. Constr. Build. Mater. 2018, 178, 612-623. [CrossRef]

38. Chen, J.; Ng, P.L.; Chu, S.H.; Guan, G.; Kwan, A. Ternary blending with metakaolin and silica fume to improve packing density and performance of binder paste. Constr. Build. Mater. 2020, 252, 119031. [CrossRef]

39. Chu, S.H.; Kwan, A.K.H. Co-addition of metakaolin and silica fume in mortar: Effects and advantages. Constr. Build. Mater. 2019, 197, 716-724. [CrossRef]

40. Chu, S.H.; Chen, J.J.; Li, L.G.; Ng, P.L.; Kwan, A.K.H. Roles of packing density and slurry film thickness in synergistic effects of metakaolin and silica fume. Powder Technol. 2021, 387, 575-583. [CrossRef]

41. Sivakrishna, A.; Adesina, A.; Awoyera, P.O.; Kumar, R.K. Green concrete: A review of recent developments. Mater. Today Proc. 2020, 27, 54-58. [CrossRef]

42. (ASTM) C150. (ASTM) C150 (Standard Specification for Portland Cement); American Society for Testing and Materials, 2017. Available online: https://global.ihs.com/doc_detail.cfm?document_name=ASTM\%20C150\%2FC150M\&item_s_key=00526215 (accessed on 5 November 2021).

43. ACI 211.1. Standard Practice for Selecting Proportions for Normal, Heavyweight, and Mass Concrete (ACI 211.1-91); ACADEMIA, 1991. Available online: https://www.academia.edu/38504100/ACI_211_1_91_Standard_Practice_for_Selecting_Proportions_ for_Normal_Heavyweight_and_Mass_Concrete (accessed on 5 November 2021).

44. Ahmad, J.; Rehman, S.U.R.; Zaid, O.; Manan, A. To study the characteristics of concrete by using high range water reducing admixture. Int. J. Mech. Prod. Eng. Res. Dev. 2020, 10, 14271-14278.

45. Materials, A.S.F.T.A. ASTM C39/C39M-12 Standard Test Method for Compressive Strength of Cylindrical Concrete Specimens; ASTM: West Conshohocken, PA, USA, 2012.

46. Designation, A. C496-71 Stand. Method Test Split. Tensile Strength Cylind Concr Specimens. 1976. Available online: https: / / www.document-center.com/standards/show/ASTM-C496 (accessed on 5 November 2021).

47. Standard, A. C78. In Stand. Test Method Flexural Strength Concr (Using Simple Beam with Third-Point Load (ASTM C78-10); ASTM Intitute: West Conshohocken, PA, USA, 2010; Available online: https://www.astm.org/c0078_c0078m-10.html (accessed on 5 November 2021).

48. Castro, J.; Bentz, D.; Weiss, J. Effect of sample conditioning on the water absorption of concrete. Cem. Concr. Compos. 2011, 33, 805-813. [CrossRef]

49. ASTM C1585-13 Standard Test Method for Measurement of Rate of Absorption of Water by Hydraulic Cement Concrete; ASTM: West Conshohocken, PA, USA, 2013.

50. Ali, B. Effect of aqueous sodium silicate on properties of recycled aggregate mortar. SN Appl. Sci. 2019, 1, 1296. [CrossRef]

51. Wang, B.; Yan, L.; Fu, Q.; Kasal, B. A Comprehensive Review on Recycled Aggregate and Recycled Aggregate Concrete. Resour. Conserv. Recycl. 2021, 171, 105565. [CrossRef]

52. Mardani-Aghabaglou, A.; Sezer, G.I.; Ramyar, K. Comparison of fly ash, silica fume and metakaolin from mechanical properties and durability performance of mortar mixtures view point. Constr. Build. Mater. 2014, 70, 17-25. [CrossRef]

53. Kou, S.; Poon, C.; Agrela, F. Comparisons of natural and recycled aggregate concretes prepared with the addition of different mineral admixtures. Cem. Concr. Compos. 2011, 33, 788-795. [CrossRef]

54. Ahmad, J.; Tufail, R.F.; Aslam, F.; Mosavi, A.; Alyousef, R.; Faisal Javed, M.; Zaid, O.; Khan Niazi, M.S. A Step towards Sustainable Self-Compacting Concrete by Using Partial Substitution of Wheat Straw Ash and Bentonite Clay Instead of Cement. Sustainability 2021, 13, 824. [CrossRef]

55. Memon, S.A.; Arsalan, R.; Khan, S.; Lo, T.Y. Utilization of Pakistani bentonite as partial replacement of cement in concrete. Constr. Build. Mater. 2012, 30, 237-242. [CrossRef]

56. Jiang, C.; Fan, K.; Wu, F.; Chen, D. Experimental study on the mechanical properties and microstructure of chopped basalt fibre reinforced concrete. Mater. Des. 2014, 58, 187-193. [CrossRef]

57. Mohan, A.; Mini, K.M. Strength Studies of SCC Incorporating Silica Fume and Ultra Fine GGBS. Mater. Today Proc. 2018, 5, 23752-23758. [CrossRef]

58. Masood, B.; Elahi, A.; Barbhuiya, S.; Ali, B. Mechanical and durability performance of recycled aggregate concrete incorporating low calcium bentonite. Constr. Build. Mater. 2020, 237, 117760. [CrossRef]

59. Zhang, M.; Li, H. Pore structure and chloride permeability of concrete containing nano-particles for pavement. Constr. Build. Mater. 2011, 25, 608-616. [CrossRef]

60. Das, C.S.; Dey, T.; Dandapat, R.; Mukharjee, B.B.; Kumar, J. Performance evaluation of polypropylene fibre reinforced recycled aggregate concrete. Constr. Build. Mater. 2018, 189, 649-659. [CrossRef]

61. Munir, M.J.; Kazmi, S.M.S.; Wu, Y.-F. Efficiency of waste marble powder in controlling alkali-silica reaction of concrete: A sustainable approach. Constr. Build. Mater. 2017, 154, 590-599. [CrossRef]

62. Guo, P.; Meng, W.; Nassif, H.; Gou, H.; Bao, Y. New perspectives on recycling waste glass in manufacturing concrete for sustainable civil infrastructure. Constr. Build. Mater. 2020, 257, 119579. [CrossRef]

63. Yoo, D.-Y.; Banthia, N.; Yang, J.-M.; Yoon, Y.-S. Mechanical Properties of Corrosion-Free and Sustainable Amorphous Metallic Fiber Reinforced Concrete. ACI Mater. J. 2016, 113, 633-643. [CrossRef] 
64. Ahmad, J.; Zaid, O.; Aslam, F.; Shahzaib, M.; Ullah, R.; Alabduljabbar, H.; Khedher, K.M. A Study on the Mechanical Characteristics of Glass and Nylon Fiber Reinforced Peach Shell Lightweight Concrete. Materials 2021, 14, 4488. [CrossRef] [PubMed]

65. Zaid, O.; Ahmad, J.; Siddique, M.S.; Aslam, F. Effect of Incorporation of Rice Husk Ash Instead of Cement on the Performance of Steel Fibers Reinforced Concrete. Front. Mater. 2021, 8, 665625. [CrossRef] 